\title{
INTEGRATED HIGH-CONTENT QUANTIFICATION OF INTRACELLULAR ROS LEVELS AND MITOCHONDRIAL MORPHOFUNCTION
}

Tom Sieprath ${ }^{122}$, Tobias D.J. Corne ${ }^{1,2}$, Peter H.G.M. Willems ${ }^{3}$, Werner J.H. Koopman ${ }^{3}$, Winnok H. De $\operatorname{Vos}^{1,2^{*}}$

\begin{abstract}
Oxidative stress arises from an imbalance between the production of reactive oxygen species (ROS) and their removal by cellular antioxidant systems. Especially under pathological conditions, mitochondria constitute a relevant source of cellular ROS. These organelles harbor the electron transport chain, bringing electrons in close vicinity to molecular oxygen. Although a full understanding is still lacking, intracellular ROS generation and mitochondrial function are also linked to changes in mitochondrial morphology. To study the intricate relationships between the different factors that govern cellular redox balance in living cells, we have developed a high-content microscopy-based strategy for simultaneous quantification of intracellular ROS levels and mitochondrial morphofunction. Here, we summarize the principles of intracellular ROS generation and removal, and we explain the major considerations for performing quantitative microscopy analyses of ROS and mitochondrial morphofunction in living cells. Next, we describe our workflow and finally, we illustrate that a multiparametric readout enables the unambiguous classification of chemically perturbed cells as well as laminopathy patient cells.
\end{abstract}

\footnotetext{
${ }^{1}$ Cell Systems and Imaging Research Group (CSI), Department of Molecular Biotechnology, Ghent University, Ghent, Belgium

${ }^{2}$ Laboratory of Cell Biology and Histology, Department of Veterinary Sciences, University of Antwerp, Antwerp, Belgium

${ }^{3}$ Department of Biochemistry (286), Radboud University Medical Centre (RUMC), Radboud Institute for Molecular Life Sciences (RIMLS), Nijmegen, The Netherlands.
} 


\section{Principles of intracellular ROS generation and removal}

Reactive oxygen species (ROS) are small, short-lived derivatives of molecular oxygen $\left(\mathrm{O}_{2}\right)$ of radical and non-radical nature (Halliwell and Gutteridge 2007). Radical ROS variants include: superoxide $\left(\mathrm{O}_{2}{ }^{-}\right)$, hydroperoxyl $\left(\mathrm{HO}_{2}{ }^{\circ}\right)$, hydroxyl $\left({ }^{\circ} \mathrm{OH}\right)$, peroxyl $\left(\mathrm{RO}_{2}{ }^{\circ}\right)$, alkoxyl $\left(\mathrm{RO}^{\circ}\right)$, carbonate $\left(\mathrm{CO}_{3}{ }^{-}\right)$, carbon dioxide $\left(\mathrm{CO}_{2}{ }^{-}\right)$, and singlet oxygen $\left(\mathrm{O}_{2}{ }^{1} \sum \mathrm{g}^{+}\right)$. Non-radical variants include: hydrogen peroxide $\left(\mathrm{H}_{2} \mathrm{O}_{2}\right)$, hypobromous acid $(\mathrm{HOBr})$, hypochlorous acid ( HOCl), ozone $\left(\mathrm{O}_{3}\right)$, singlet oxygen $\left(\mathrm{O}_{2}{ }^{1} \Delta \mathrm{g}\right)$, organic peroxides ( $\left.\mathrm{ROOH}\right)$, peroxynitrite $\left(\mathrm{ONOO}^{-}\right)$, peroxynitrate $\left(\mathrm{O}_{2} \mathrm{NOO}^{-}\right)$, nitrosoperoxycarbonate $\left(\mathrm{ONOOCO}_{2}^{-}\right)$and peroximonocarbonate $\left(\mathrm{HOOCO}_{2}^{-}\right)$(Halliwell and Gutteridge 2007). Of these ROS, ONOO and $\mathrm{O}_{2} \mathrm{NOO}^{-}$are also reactive nitrogen species (RNS). RNS further include nitric oxide $\left(\mathrm{NO}^{\circ}\right)$, nitrogen dioxide $\left(\mathrm{NO}_{2}{ }^{\circ}\right)$, nitrate radical $\left(\mathrm{NO}_{3}{ }^{\circ}\right)$ and many other nitrogen derivatives. ROS were originally described as molecular constituents of the defense system of phagocytic cells, but it has become clear that besides their damaging properties, they also function as signaling molecules and mediate a variety of other cellular responses including cell proliferation, differentiation, gene expression and migration (Lambeth 2004; Bartz and Piantadosi 2010).

\section{Intracellular ROS metabolism}

ROS can be generated at various sites in the cell (Fig. 1A). This can be either deliberately, e.g. by NADPH oxidases (NOX), or as a byproduct, e.g. during normal cellular respiration in mitochondria (Babior 1999; Turrens 2003; Murphy 2009). The NOX family of NADPH oxidases (NOX1, NOX2, NOX3, NOX4, NOX5, DUOX1 and DUOX2) are proteins that transport electrons $\left(\mathrm{e}^{-}\right)$from NADPH across biological membranes (plasma or endomembranes) (Bedard and Krause 2007; Dupre-Crochet et al. 2013). The activation mechanisms and tissue distribution of the isoforms differ but they all use $\mathrm{O}_{2}$ as $\mathrm{e}^{-}$-acceptor, producing $\mathrm{O}_{2}{ }^{--}$. Through ROS generation, they play a role in many cellular processes including host defense, regulation of gene expression and cell differentiation (Bedard and Krause 2007). Despite their sometimes significant contribution to the global ROS pools, NOX are not the predominant source of intracellular ROS. Mitochondria are considered the major culprit, in particular under pathological conditions. Mitochondrial ROS are generated as a byproduct of the oxidative phosphorylation (OXPHOS, cf. below).

Irrespective of its source, ROS production generally starts with the reduction of $\mathrm{O}_{2}$ to $\mathrm{O}_{2}{ }^{\circ-}$, which is the precursor of most other ROS (Fig. 2A). Either spontaneously or, more likely, catalyzed by a superoxide dismutase (SOD), $\mathrm{O}_{2}{ }^{-}$is converted into $\mathrm{H}_{2} \mathrm{O}_{2}$ at a rate close to the diffusion limit $\left(\mathrm{k}=2 \cdot 10^{9} \mathrm{M}^{-1} \mathrm{~s}^{-1}\right.$ at $\mathrm{pH}$ 7.4) (Weisiger and Fridovich 1973; Boveris and Chance 1973; Loschen et al. 1974; Auchère and Rusnak 2002). In turn, $\mathrm{H}_{2} \mathrm{O}_{2}$ can be converted into water $\left(\mathrm{H}_{2} \mathrm{O}\right)$ by several enzymes including peroxiredoxins, catalase (CAT) and glutathione peroxidases (GPX) (Gupta et al. 2012). Proper function of these systems further requires the action of glutathione reductase (GR), thioredoxin (TRX), thioredoxin reductase (TRXR), glutaredoxin (GRX), peroxiredoxin (PRX), sulfiredoxin (SRX), the glutathione (GSH)synthesizing enzymes glutathione synthase (GS), glutamate cysteine ligase (GCL) and ceruloplasmin (Gupta et al. 2012). In addition to enzymatic systems, cells and tissues also contain antioxidants of non-enzymatic nature including glutathione (GSH), thioredoxin (TRX), phytochemicals, vitamins (A,C,E), ceruloplasmin and taurine (Gupta et al. 2012). The cofactor NADPH (the reduced form of nicotinamide adenine dinucleotide phosphate) is central to cellular ROS removal through the GSH and TRX/PRX systems (Fig. 2A). In mitochondria, NADPH is mainly produced via: (i) $\mathrm{NADP}^{+}$-dependent isocitrate dehydrogenase and malic enzyme, and (ii) nicotinamide nucleotide transhydrogenase (Nnt). The latter enzyme utilizes the proton motive force (PMF) to generate NADPH from NADH 
and NADP ${ }^{+}$(Lopert and Patel 2014). Besides the conversion into $\mathrm{H}_{2} \mathrm{O}_{2}, \mathrm{O}_{2}{ }^{--}$can also react with nitric oxide $\left(\mathrm{NO}^{\circ}\right)$, produced in a two-step reaction from L-arginine (L-arg), catalyzed by nitric oxide synthases (NOS). This gives rise to the production of reactive nitrogen species (RNS) peroxynitrite $\left(\mathrm{ONOO}^{-}\right)$and peroxynitrous acid $(\mathrm{ONOOH})$. Various other reactions downstream of $\mathrm{ONOO}^{-}$lead to formation of ${ }^{\circ} \mathrm{OH}, \mathrm{CO}_{3}{ }^{-}$and $\mathrm{NO}_{2}{ }^{\circ}$ (Fig. 2A) (Radi et al. 2002; Szabó et al. 2007). In the presence of ferric iron $\left(\mathrm{Fe}^{3+}\right)$ the $\mathrm{O}_{2}{ }^{-{ }^{-}}$anion is converted into $\mathrm{O}_{2}$ and ferrous iron $\left(\mathrm{Fe}^{2+}\right.$ ), which can further react with $\mathrm{H}_{2} \mathrm{O}_{2}$ to reform $\mathrm{Fe}^{3+}$, hydroxide $\left(\mathrm{OH}^{-}\right)$and the highly reactive ${ }^{\circ} \mathrm{OH}$ (Fig. 2A)(Thomas et al. 2009). ${ }^{\circ} \mathrm{OH}$ is one of the strongest oxidants in nature and is extremely damaging to biomolecules like DNA, proteins and lipids (Franco et al. 2008; Marchi et al. 2012). It can initiate formation of lipid (L') and lipid peroxyl (LOO') radicals (lipid peroxidation), which is counterbalanced by the action of various antioxidant systems including vitamin $\mathrm{E} / \alpha$-tocopherol $(\alpha-\mathrm{TOH})$, vitamin $\mathrm{C} /$ ascorbate $\left(\mathrm{AscH}^{-}\right), \mathrm{NADPH} / \mathrm{NADP}^{+}, \mathrm{GSH}, \mathrm{GPX} / \mathrm{GST}$ and GR (Fig. 2A). Ultimately, sustained stimulation of lipid peroxidation will lead to formation of pentane and the reactive aldehydes malondialdehyde (MDA) and 4-hydroxynonenal (4-HNE). When generated at low levels, 4HNE can interact with signaling targets, including JNK, P38 MAPK, cell cycle regulators, $\mathrm{PKC} \beta$, and $\mathrm{PKC} \delta$, leading to numerous cellular responses, ranging from increased expression of the antioxidant enzyme TRXR1 to irreversible cytotoxic injuries and cell death(Chen et al. 2005; Riahi et al. 2010). Mitochondrial aldehyde dehydrogenase 2 (ALDH2) can protect against oxidative stress by detoxification of these cytotoxic aldehydes (Chiu et al. 2015).

ROS can react covalently with certain atomic elements in biological macromolecules (Fig. 2B) (Nathan and Cunningham-Bussel 2013). At low ROS levels, these modifications are usually reversible, whereas at high ROS levels, they are not. Reversibility is also confined to specific atoms: reversible modifications occur on selenium (Se; in seleno-Cys) and sulfur (S; in certain Cys and Met), whereas iron-sulfur (Fe-S) clusters and carbon (C) atoms (Arg, Lys, Pro, Thr and nucleosides) are irreversibly modified. Reactions of primary ROS with proteins include reversible oxidative formation of methionine sulfoxide (by ${ }^{\circ} \mathrm{OH}$ ) and irreversible formation of 2-oxo-histidine (by $\mathrm{H}_{2} \mathrm{O}_{2} / \mathrm{Fe}^{2+}$ ), chlorotyrosine (by $\mathrm{HOCl}$ ) and protein carbonyls (by $\left.{ }^{\circ} \mathrm{OH}\right)$ (Dickinson and Chang 2011). When protein thiol $(\mathrm{SH})$ groups (pKa $\sim 8.5$ ) are within a basic environment (such as the mitochondrial matrix) or have their $\mathrm{pKa}$ lowered by proximity to positively charged amino acids they deprotonate and are present in their thiolate ( $\mathrm{S}^{-}$) form (Fig. 2B) (Mailloux et al. 2013). Protein thiolate groups reversibly react with ROS $\left(\mathrm{H}_{2} \mathrm{O}_{2}, \mathrm{HOCl}\right)$ to form protein sulfinic acid $(\mathrm{SOH})$. In the presence of high $\mathrm{H}_{2} \mathrm{O}_{2}$ levels, the $\mathrm{SOH}$ form is subsequently and irreversibly converted into sulfinic acid $\left(\mathrm{SO}_{2} \mathrm{H}\right)$ and sulfonic acid $\left(\mathrm{SO}_{3} \mathrm{H}\right)$ forms. The thiolate form can also react with: (i) glutathione disulfide (GSSG) to form S-glutathionylated (SSG) proteins and (ii) RNS to form S-nitrosated/S-nitrosylated (SNO) proteins (Benhar et al. 2009; Grek et al. 2013). Starting from the SOH form, the reaction of protein thiols with GSH also leads to formation of S-glutathionylated proteins. By reacting with other $\mathrm{SH}$ groups, the $\mathrm{SOH}$ form can induce inter- or intra-molecular disulfide bond formation (Fig. 2B). The SH groups in the SSG, SNO and disulfide proteins can be reformed via various reactions involving GRX, TRX, TRXR and NADPH (Fig. 2B), allowing redox-dependent cell signaling events (Benhar et al. 2009; Nakamura and Lipton 2011; Murphy 2012; Groitl and Jakob 2014).

There is a subtle balance between the production and removal of the different ROS molecules to maintain their intracellular concentration at a physiological level. Any perturbation to this fragile steady-state that increases intracellular ROS provokes oxidative stress, a phenomenon associated with the natural aging process, as well as various multispectrum diseases including cancer and laminopathies (Harman 1956; Naderi et al. 2006; Moylan and Reid 2007; Caron et al. 2007; Salmon et al. 2010; Sieprath et al. 2012). 


\section{Range of action of ROS}

A surplus of ROS is highly unwanted as it allows them to interact with various cellular constituents. However, to react with biomolecules, ROS need to be able to reach them. Once generated, the range-of-action of individual ROS differs substantially. For instance, in the presence of GSH $(2 \mathrm{mM})$, values of $50 \mu \mathrm{m}$ and $1.5 \mathrm{~mm}$ were computed for $\mathrm{ONOO}^{-}$and $\mathrm{H}_{2} \mathrm{O}_{2}$, respectively (Winterbourn 2008). The same study reported that the range-of-action for $\mathrm{H}_{2} \mathrm{O}_{2}$ dropped to $<7 \mu \mathrm{m}$, in the presence of $20 \mu \mathrm{M}$ PRX2 (the main $\mathrm{H}_{2} \mathrm{O}_{2}$-removing enzyme) and was even lower for ${ }^{\circ} \mathrm{OH}(0.35 \mu \mathrm{m})$. In aqueous solution the average $3 \mathrm{D}$ diffusion distance or "Kuramoto length" $(\Delta \mathrm{x})$ was calculated to be $<0.16 \mu \mathrm{m}$ for $\mathrm{O}_{2}{ }^{-}$and between $0.23-0.46$ $\mu \mathrm{m}$ for $\mathrm{H}_{2} \mathrm{O}_{2}$ (Koopman et al. 2010). Using the Einstein-Smoluchowski equation (1), diffusion distances of $50 \mu \mathrm{m}\left(\mathrm{O}_{2}{ }^{--}\right.$, in the absence of SOD), $0.4 \mu \mathrm{m}\left(\mathrm{O}_{2}{ }^{--}\right.$, in the presence of SOD), $3000 \mu \mathrm{m}\left(\mathrm{H}_{2} \mathrm{O}_{2}\right), 0.005 \mu \mathrm{m}$ ( $\mathrm{OH}$, in aqueous solution), $0.07 \mu \mathrm{m}\left(\mathrm{CO}_{3}{ }^{\circ}{ }^{\circ}\right), 0.13 \mu \mathrm{m}$ $\left(\mathrm{NO}_{2}{ }^{\circ}\right)$ and $0.07 \mu \mathrm{m}\left(\mathrm{O}_{2}{ }^{1}\right)$ were predicted (Cardoso et al. 2012).

$$
D=\frac{k_{B} T}{6 \pi \eta r}
$$

$\left(\mathrm{D}=\right.$ diffusion constant; $\mathrm{k}_{\mathrm{B}}=$ Boltzann's constant; $\mathrm{T}=$ absolute temperature; $\eta=$ dynamic viscosity; $r=$ radius of the spherical particle)

Importantly, several ROS, including $\mathrm{O}_{2}{ }^{--}$, are charged molecules, which prevents their passive transmembrane permeation. When generated in the mitochondrial matrix, $\mathrm{O}_{2}{ }^{\circ-}$ is highly unlikely to leave this compartment unless facilitated. Currently there are no reports of superoxide permeation of the inner membrane. However, it has been proposed that the voltage-dependent anion channel (VDAC) in the mitochondrial outer membrane could mediate $\mathrm{O}_{2}{ }^{\circ-}$ release from mitochondria (Han et al. 2003). Taken together, due to their physicochemical properties and the action of (non)enzymatic conversion cascades, various ROS types display different ranges of action within cells and subcellular compartments including mitochondria. This strongly suggests that both ROS-induced damage and signaling are affected by restricted diffusion and compartmentalization (Winterbourn 2008). In this respect, it appears that mitochondria-generated $\mathrm{O}_{2}{ }^{--}$acts locally, whereas $\mathrm{H}_{2} \mathrm{O}_{2}$ and $\mathrm{NO}^{\circ}$, owing to their membrane permeability and relative stability, can function as both a cytosolic and extracellular messenger $\left(\mathrm{t}_{1 / 2}\right.$ for $\mathrm{H}_{2} \mathrm{O}_{2}$ is $10^{-2} \mathrm{~ms}$ and for $\mathrm{NO}^{\bullet}$ between 1-30 s, compared to $10^{-3} \mathrm{~ms}$ and $10^{-6} \mathrm{~ms}_{\text {for }} \mathrm{O}_{2}{ }^{\circ-}$ and ${ }^{\circ} \mathrm{OH}$ ) (Radi et al. 2002; Boveris et al. 2006; Giorgio et al. 2007; Hamanaka and Chandel 2010). The diffusion properties of $\mathrm{H}_{2} \mathrm{O}_{2}$ likely depend on its site of generation and (local) conversion, since cytoplasmic microdomains of elevated $\mathrm{H}_{2} \mathrm{O}_{2}$ levels were demonstrated in cells stimulated with growth factors, suggesting that this type of ROS does not freely diffuse through the cytoplasm (Rhee et al. 2012; Mishina et al. 2012).

\section{Mitochondria are prime sources and targets of ROS}

In total, mitochondria account for $90 \%$ to $95 \%$ of the cellular oxygen consumption and up to $3 \%$ of that pool can be converted into $\mathrm{O}_{2}{ }^{--}$, depending on the mitochondrial functional state or 'mitochondrial health' (Marchi et al. 2012). A widely used indicator of mitochondrial health is the magnitude of the membrane potential $\left(\Delta \psi_{\mathrm{m}}\right)$ across the mitochondrial inner membrane. This potential is central to virtually all major (bioenergetic) functions of the mitochondrion, as it reflects the proton motive force that drives OXPHOS and mitochondrial $\mathrm{Ca}^{2+}$ uptake (Turrens 2003). $\Delta \psi_{\mathrm{m}}$ is sustained by the action of the four complexes (complex I-IV) of the electron transport chain (ETC), located on the inner mitochondrial membrane, and the adjoined export of protons into the intermembrane space (Fig. 1B). Proton backflow through the $\mathrm{F}_{0} \mathrm{~F}_{1}$-ATPase (complex V) is then used to drive the production of ATP production in the 
mitochondrial matrix. ROS can be produced at many locations inside the mitochondrion (Fig. 1B), but it generally results from electron leakage at complex I of the electron transport chain (ETC) when $\Delta \psi_{\mathrm{m}}$ is highly negative. However, both de- and hyperpolarization have been associated with increased ROS production (Korshunov et al. 1997; Miwa and Brand 2003; Verkaart et al. 2007; Murphy 2009; Lebiedzinska et al. 2010). Various mitochondrial proteins are susceptible to reversible and irreversible redox modifications, allowing local regulation of their function and/or affecting pathological processes. For instance, reversible S-nitrosylation of Complex I at Cys39 of the ND3 subunit decreased ROS production, oxidative damage and tissue necrosis and thereby protected against injury during cardiac ischemia-reperfusion in vivo (Chouchani et al. 2013).

Although a full understanding is still lacking, net mitochondrial morphology, a result of continuous fusion and fission events, appears to be linked to mitochondrial function, ROS generation and redox state as well (Willems 2015). An accumulating body of evidence points to direct involvement of ROS (and RNS) in the short-term regulation of mitochondrial morphology and function via non-transcriptional pathways, i.e., through reversible and nonreversible redox modifications (S-nitrosylation, disulfide bond formation) on/in proteins involved in the fission-fusion machinery of mitochondria (Willems 2015). Fragmentation appears correlated with increased ROS production and apoptosis (Koopman et al. 2007; Archer 2013), while a more filamentous phenotype has been linked to nutrient starvation and protection against mitophagy (Rambold et al. 2011).

Given their close relationship, intracellular ROS levels and mitochondrial morphofunction should be studied together in living cells so as to better understand their interconnection during normal and pathological conditions. This is why we have developed a quantitative high-content assay for simultaneous quantification of intracellular ROS, mitochondrial morphology and $\Delta \psi_{\mathrm{m}}$. Before we explain the workflow in detail, we describe some general considerations required for live cell ROS and mitochondrial imaging. 


\section{Considerations for quantifying redox biology and mitochondrial function in living cells using fluorescence microscopy}

Microplate readers are regularly used to measure fluorescence intensities, but the readout is highly prone to confounding factors, such as variable cell density and autofluorescence. Although flow cytometry measures all cells individually, which greatly increases sensitivity and accuracy, this technique does not provide spatiotemporal information (e.g. no subcellular localization, no time-dependent kinetics) and imposes an operational stress factor (cell detachment) when working with adherent cell cultures. These disadvantages are avoided when using fluorescence microscopy. Microscopy allows gauging redox biology and mitochondrial function in individual adherent cells through time at subcellular resolution and with high sensitivity, both pre- and post-stimulus, i.e., in fluxo. However, to enable robust and accurate measurements of intracellular ROS and individual mitochondria, all aspects of the imaging pipeline, from sample preparation to image analysis, have to be thoroughly standardized. In this part, we highlight some of the major considerations.

\section{Cell culture conditions}

Culture conditions prior to the measurements have to be meticulously controlled in order to obtain robust and reproducible results. For instance, the composition of the culture medium as well as the imaging buffer can greatly affect mitochondrial morphology and function. Nutrient starvation generally leads to a more filamentous mitochondrial phenotype (Rambold et al. 2011; Gomes et al. 2011), while high glucose concentrations have been linked to increased ROS production and mitochondrial fission (Yu et al. 2006; Trudeau et al. 2011). Cells should be seeded at least $24 \mathrm{~h}$ before actual measurements, at fixed splitting ratios so as to obtain a sub-confluent culture of $70 \%-80 \%$ (substrate occupation) at the time point of measurement. This guarantees optimal performance of downstream image analyses (in particular cell segmentation). Furthermore, imaging buffer/medium should be devoid of potential autofluorescent components, such as phenol-red, riboflavin or tryptophan, in order to reduce non-specific background intensity (Frigault et al. 2009). Also, to minimize the influence of plate effects, sample distribution should be homogenized or randomized across the plate and the outer wells should not be used for measurements since they are prone to edge effects (they can however be used to take background images for a downstream flatfield correction).

\section{Sensors}

A second point of attention pertains to the selection of the appropriate reporter (Table 1). As most ROS molecules tend to have a short lifetime (nanoseconds to seconds), fluorescent detection of intracellular redox changes demands sensitive reporter dyes with fast and reversible binding kinetics, and high dynamic range (Dikalov and Harrison 2014). Ideally, they also show little or no photobleaching or (photo)toxicity and loading is quick and easy. Currently available ROS probes can be subdivided into two categories: synthetic small molecule dyes and genetically encoded fluorescent proteins. The most commonly used small molecule ROS probes are dihydroethidium (DHE), mitochondrial targeted DHE (MitoSOX) and the chemically reduced and acetylated forms of 2',7'-di- chlorofluorescein (DCF) (Wang et al. 2013). CM- $\mathrm{H}_{2}$ DCFDA (5-(and-6)-chloromethyl-2',7'-dichlorodihydrofluorescein diacetate, acetyl ester) is a widely used chloromethyl derivative of $\mathrm{H}_{2}$ DCFDA that is used to measure general intracellular ROS levels. It diffuses passively into the cell where its acetate groups are cleaved by intracellular esterases, decreasing its capacity to traverse the cell membrane, and thereby trapping it inside the cell. Its thiol-reactive chloromethyl group allows for covalent binding to intracellular components, increasing retention of the dye even 
further. Following oxidation, highly fluorescent DCF is formed. With an excitation maximum of $502 \mathrm{~nm}$ and an emission peak of $523 \mathrm{~nm}$, DCF fluorescence can be readily monitored using standard filter combinations for GFP or FITC (Tarpey et al. 2004; Gomes et al. 2005; Koopman et al. 2006). Other general small molecule ROS probes include Thioltracker ${ }^{\circledR}$ and the CellROX ${ }^{\circledR}$ family of indicators (Life Technologies ${ }^{\mathcal{O}}$ ). Dyes that are more specific to certain types of ROS exist as well. DHE is generally used as a probe for $\mathrm{O}_{2}{ }^{-}$(Zhao et al. 2003). The reaction between $\mathrm{DHE}$ and $\mathrm{O}_{2}{ }^{-}$generates highly red fluorescent 2hydroxyethidium $\left(2-\mathrm{OH}-\mathrm{E}^{+}\right.$; ex. $518 \mathrm{~nm}$, em. $\left.605 \mathrm{~nm}\right)$. Reaction with other oxidants, however, can produce ethidium $\left(\mathrm{E}^{+}\right)$, which strongly binds DNA, is also red fluorescent (ex. $525 \mathrm{~nm}$, em. $616 \mathrm{~nm}$ ) and is often present at a much higher concentration (Zielonka and Kalyanaraman 2010). Discrimination between these two is still be possible, however, due to an extra excitation band between 350 and $400 \mathrm{~nm}$ for $2-\mathrm{OH}-\mathrm{E}^{+}$(Robinson et al. 2006). However, as the ratio $\mathrm{E}^{+} / 2-\mathrm{OH}-\mathrm{E}^{+}$is often 10 or more, contribution of $\mathrm{E}^{+}$might still be significant (Zielonka and Kalyanaraman 2010). MitoSOX is a DHE derivative coupled to a positively charged triphenylphosphonium group $\left(\mathrm{TPP}^{+}\right)$, enabling efficient targeting to the mitochondria for selective detection of mitochondrial $\mathrm{O}_{2}{ }^{--}$(Robinson et al. 2008). The recently described HKSOX1 family of probes is also specific for $\bullet \mathrm{O}_{2}(\mathrm{Hu}$ et al. 2015) and a family of boronate-based sensors (peroxy family e.g. PF1, PF3, PG1, PO1, PY1, MitoPY1...) targeting to the cytosol or the mitochondria is used for the detection of $\mathrm{H}_{2} \mathrm{O}_{2}$ (Chang et al. 2004; Miller et al. 2007; Dickinson et al. 2010a; Dickinson et al. 2010b). $\mathrm{H}_{2} \mathrm{O}_{2}$-mediated removal of a boronate group greatly increases fluorescence of these sensors. They also display a range of fluorescent wavelengths, making them useful for multicolor experiments. For a more extensive overview of small molecule fluorescent probes for ROS the reader is referred to Gomes et al. (Gomes et al. 2005). Next to small molecule fluorescent probes, ROS can also be monitored using genetically encoded fluorescent protein based probes. While labeling is more complex, usually involving liposome- or virus-based transfection procedures, selectivity of these dyes is generally higher. Moreover, genetic reporters can easily be targeted to a variety of intracellular destinations and they are maintained for prolonged periods of time allowing long-term and transgeneration follow-up. They either are ROS-sensitive fluorophores or standard fluorophores fused to ROS-sensing domains borrowed from other proteins like SoxR and OxyR, i.e., transcription factors found in E.coli that become activated by oxidation with $\mathrm{O}_{2}{ }^{-{ }^{-}}$or $\mathrm{H}_{2} \mathrm{O}_{2}$, respectively (Zheng et al. 1998; Fujikawa et al. 2012). In SoxR the regulatory domain contains a $2 \mathrm{Fe}-2 \mathrm{~S}$ cluster, while that of OxyR has several redox active cysteine residues. Both of them undergo a significant conformational change upon activation. In order to translate this into a quantifiable change in fluorescence, these domains are linked to circularly permuted (cp) versions of fluorescent proteins (Topell et al. 1999; Baird et al. 1999). The HyPer family of fluorescent probes was created by inserting a cpYFP in the regulatory domain of OxyR (Belousov et al. 2006; Markvicheva et al. 2011; Bilan et al. 2013). HyPer acts as a ratiometric $\mathrm{H}_{2} \mathrm{O}_{2}$ probe with 2 excitation maxima (420 and $500 \mathrm{~nm}$ ) corresponding to the protonated and anionic forms of the protein, respectively, and one emission maximum $(516 \mathrm{~nm})$. Upon oxidation, a disulfide bond is formed between Cys 199 and Cys 208, resulting in a decrease of the $420 \mathrm{~nm}$ excitation peak and a proportional increase of the $500 \mathrm{~nm}$ excitation peak. This ratiometric determination greatly reduces the influence of expression level differences between individual cells. Unfortunately, HyPer is partially sensitive to $\mathrm{pH}$ changes. Acidification of the cellular environment leads to protonation, thus mimicking reduction of the probe; alkalization on the other hand mimics oxidation (Belousov et al. 2006). SypHer, a $\mathrm{H}_{2} \mathrm{O}_{2-}$ insensitive HyPer variant (C199S) is a $\mathrm{pH}$ sensor and can be used as a control (Poburko et al. 2011). Another family of fluorescent protein based redox-sensitive probes are the roGFPs, which were created by introducing oxidizable cysteine residues on the outside of the $\beta$-barrel 
structure of GFP near the location of the chromophore. They can be used to ratiometrically measure intracellular redox balance (GSH/GSSG-ratio). roGFPs, just like HyPer, have 2 excitation peaks, which correspond to their oxidized and reduced states, but in contrast to HyPer they are considered insensitive to $\mathrm{pH}$ (Lukyanov and Belousov 2014). One of the drawbacks of roGFP reporters is their slow kinetics. A fusion between roGFP and glutaredoxin 1 (Grx1-roGFP) resulted in a probe with faster kinetics (Gutscher et al. 2008). However, it still takes minutes or longer to equilibrate with cellular redox potential changes, which is still too slow to detect fast transient events (Meyer and Dick 2010). Another variant is Orp1-roGFP, a fusion between roGFP and the yeast peroxidase Orp1, which functions as an intracellular, ratiometric, $\mathrm{pH}$-stable $\mathrm{H}_{2} \mathrm{O}_{2}$ probe (Gutscher et al. 2009). Its response to $\mathrm{H}_{2} \mathrm{O}_{2}$ is similar to that observed with HyPer, although oxidation is slower (Gutscher et al. 2009). Next to direct ROS probes, one could also use probes that assess ROS indirectly by measuring the downstream damage such as lipid peroxidation. C11-BODIPY ${ }^{581 / 591}$, for example, is a ratiometric sensor for lipid peroxidation (Drummen et al. 2002), while MitoPeroX (a mitochondria targeted derivative of C11- BODIPY ${ }^{581 / 591}$ ) is a ratiometric probe for the specific assessment of mitochondrial phospholipid peroxidation (Prime et al. 2012).

Several fluorescent dyes have also been developed for measuring mitochondrial morphology and $\Delta \psi_{\mathrm{m}}$. They all are cell-permeant and become readily sequestered by active mitochondria in a $\Delta \psi_{\mathrm{m}}$-dependent manner (Iannetti et al. 2015). Of these, the red-orange fluorescent tetramethylrhodamine methyl ester (TMRM) is one of the most efficient because it equilibrates fastest across membranes, is least toxic and demonstrates the lowest aspecific binding (Nicholls 2012). With its excitation and emission maxima being 550nm and $576 \mathrm{~nm}$, respectively, it is also compatible with many probes that are fluorescent in the GFP region, like the HyPers and roGFPs, or CM-H ${ }_{2}$ DCFDA. MitoTracker ${ }^{\circledR}$ dyes (MTRs) should only be used for morphological analysis. Although they are also sequestered to the mitochondria based on $\Delta \psi_{\mathrm{m}}$, they are retained there as a result of reaction with mitochondrial biomolecules, making it impossible to measure dynamic changes of $\Delta \psi_{\mathrm{m}}$ (Dong et al. 2013).

Table 1: Characteristics and usage of common ROS, redox and mitochondrial probes

\begin{tabular}{|c|c|c|c|c|c|}
\hline Type & Name & Indicator for & $\begin{array}{l}\mathrm{Ex} / \mathrm{Em} \\
(\mathrm{nm})\end{array}$ & Remarks & References \\
\hline \multirow{6}{*}{ Chemical } & DHE & $\mathrm{O}_{2}{ }^{\circ-}$ & $518 / 605$ & $\begin{array}{l}\text { Excitation between } \\
350-400 \text { nm to } \\
\text { differentiate } 2-\mathrm{OH}- \\
\mathrm{E}^{+} \text {from } \mathrm{E}^{+}\end{array}$ & $\begin{array}{l}\text { (Zielonka and } \\
\text { Kalyanaraman } \\
\text { 2010), } \\
\text { (Robinson et al. } \\
2006 \text { ) }\end{array}$ \\
\hline & $\begin{array}{l}\text { MitoSOX - } \\
\text { Red }\end{array}$ & $\begin{array}{l}\text { Mitochondrial } \\
\mathrm{O}_{2}^{--}\end{array}$ & $518 / 605$ & & $\begin{array}{l}\text { (Robinson et al. } \\
\text { 2008), (Forkink } \\
\text { et al. 2015) }\end{array}$ \\
\hline & $\begin{array}{l}\text { CM- } \\
\mathrm{H}_{2} \text { DCFDA }\end{array}$ & General ROS & $502 / 523$ & & $\begin{array}{l}\text { (Koopman et al. } \\
\text { 2006), (Sieprath } \\
\text { et al. 2015) }\end{array}$ \\
\hline & $\begin{array}{l}\text { C11- } \\
\text { BODIPY }\end{array}$ & \multirow{3}{*}{$\begin{array}{l}\text { Lipid } \\
\text { peroxidation } \\
\text { Mitochondrial } \\
\text { lipid } \\
\text { peroxidation } \\
\text { Mitochondrial } \\
\text { morphology } \\
\text { and } \Delta \psi_{\mathrm{m}}\end{array}$} & $\begin{array}{l}490 / 520 \\
580 / 590\end{array}$ & \multirow{3}{*}{$\begin{array}{l}\text { oxidized product: } \\
490 / 520 ; \text { reduced } \\
\text { product: } 580 / 590 ; \\
\text { also } 490 / 520 \text { and } \\
590 \text { can be used }\end{array}$} & $\begin{array}{l}\text { (Drummen et al. } \\
2002 \text { ) }\end{array}$ \\
\hline & MitoPerOx & & $\begin{array}{l}490 / 520 \\
580 / 590\end{array}$ & & $\begin{array}{l}\text { (Prime et al. } \\
\text { 2012) }\end{array}$ \\
\hline & TMRM & & $550 / 576$ & & $\begin{array}{l}\text { (Nicholls 2012), } \\
\text { (Koopman et al. } \\
\text { 2008) }\end{array}$ \\
\hline
\end{tabular}




\begin{tabular}{|c|c|c|c|c|c|}
\hline & MTRs & $\begin{array}{l}\text { Mitochondrial } \\
\text { morphology }\end{array}$ & - & $\begin{array}{lr}\text { Multiple } & \text { MTRs } \\
\text { with } & \text { different } \\
\text { ex/em } & \\
\end{array}$ & (Chazotte 2011) \\
\hline & PF3 & $\mathrm{H}_{2} \mathrm{O}_{2}$ & $492 / 515$ & \multirow{5}{*}{$\begin{array}{l}\text { These probes are } \\
\text { all sensitive for } \\
\mathrm{H}_{2} \mathrm{O}_{2} \text { but they } \\
\text { exhibit different } \\
\text { fluorescence } \\
\text { ex/em, making } \\
\text { them compatible } \\
\text { with other probes }\end{array}$} & $\begin{array}{l}\text { (Dickinson et al. } \\
\text { 2010a) }\end{array}$ \\
\hline & PG1 & $\mathrm{H}_{2} \mathrm{O}_{2}$ & $460 / 510$ & & $\begin{array}{l}\text { (Miller et al. } \\
\text { 2007) }\end{array}$ \\
\hline & PO1 & $\mathrm{H}_{2} \mathrm{O}_{2}$ & $540 / 565$ & & $\begin{array}{l}\text { (Dickinson et al. } \\
\text { 2010a) }\end{array}$ \\
\hline & PY1 & $\mathrm{H}_{2} \mathrm{O}_{2}$ & $519 / 548$ & & $\begin{array}{l}\text { (Dickinson et al. } \\
\text { 2010a) }\end{array}$ \\
\hline & MitoPY1 & $\begin{array}{l}\text { Mitochondrial } \\
\mathrm{H}_{2} \mathrm{O}_{2}\end{array}$ & $510 / 528$ & & $\begin{array}{l}\text { (Dickinson et al. } \\
\text { 2013) }\end{array}$ \\
\hline \multirow{7}{*}{ Protein } & HyPer 1 & $\mathrm{H}_{2} \mathrm{O}_{2}$ & $\begin{array}{l}420 \text { and } \\
500 / 516\end{array}$ & \multirow{3}{*}{$\begin{array}{l}\text { Hyper 2: better } \\
\text { dynamic range, } \\
\text { slower kinetics; } \\
\text { Hyper 3: better } \\
\text { dynamic range and } \\
\text { better kinetics }\end{array}$} & $\begin{array}{l}\text { (Belousov et al. } \\
2006 \text { ) }\end{array}$ \\
\hline & HyPer 2 & $\mathrm{H}_{2} \mathrm{O}_{2}$ & $\begin{array}{l}420 \text { and } \\
500 / 516\end{array}$ & & $\begin{array}{l}\text { (Markvicheva et } \\
\text { al. 2011) }\end{array}$ \\
\hline & HyPer 3 & $\mathrm{H}_{2} \mathrm{O}_{2}$ & $\begin{array}{l}420 \text { and } \\
500 / 516\end{array}$ & & $\begin{array}{lll}\text { (Bilan et al. } \\
\text { 2013) }\end{array}$ \\
\hline & roGFP1 & $\begin{array}{l}\text { GSH redox } \\
\text { potential }\end{array}$ & $\begin{array}{l}400 \text { and } \\
475 / 509\end{array}$ & \multirow{4}{*}{$\begin{array}{l}\text { roGFP2: superior } \\
\text { to roGFP1; Grx1- } \\
\text { roGFP2: } \\
\text { kinetics } \\
\text { (equilibration } \\
\text { : minutes) }\end{array}$} & $\begin{array}{l}\text { (Hanson et al. } \\
\text { 2004) }\end{array}$ \\
\hline & roGFP2 & $\begin{array}{l}\text { GSH redox } \\
\text { potential }\end{array}$ & $\begin{array}{l}400 \text { and } \\
490 / 509\end{array}$ & & $\begin{array}{l}\text { (Dooley et al. } \\
2004 \text { ) }\end{array}$ \\
\hline & $\begin{array}{l}\text { Grx1- } \\
\text { roGFP2 }\end{array}$ & $\begin{array}{l}\text { GSH redox } \\
\text { potential }\end{array}$ & $\begin{array}{l}400 \text { and } \\
490 / 509\end{array}$ & & $\begin{array}{l}\text { (Gutscher et al. } \\
\text { 2008) }\end{array}$ \\
\hline & $\begin{array}{l}\text { Orp1- } \\
\text { roGFP2 }\end{array}$ & $\mathrm{H}_{2} \mathrm{O}_{2}$ & $\begin{array}{l}400 \text { and } \\
490 / 509\end{array}$ & & $\begin{array}{l}\text { (Gutscher et al. } \\
\text { 2009) }\end{array}$ \\
\hline
\end{tabular}

\section{Microscopy}

When performing live cell imaging, optimal cellular health condition is crucial to ensure that the physiological and biological processes under investigation are not altered in any way. For mammalian cells, the temperature must ideally be kept stable at $37^{\circ} \mathrm{C}, \mathrm{pH}$ should be at a physiological level $(\sim \mathrm{pH}=7.2-7.4)$ and changes in osmolarity have to be avoided by minimizing evaporation (Frigault et al. 2009). However, to reduce externalization and vacuolization of internalized dyes, measurements are often performed at lower temperatures (Staljanssens et al. 2012). Temperature control can be achieved by means of a large incubator enclosing the whole microscope, or a stagetop incubator in combination with objective heaters. To minimize thermally induced focus drift along the z-axis, samples should be allowed to equilibrate on the microscope before imaging. When using bicarbonate-based culture medium, a $\mathrm{CO}_{2}$ incubation chamber or HEPES-based buffer has to be used to keep $\mathrm{pH}$ at a physiological level (Casey 2006). To avoid evaporation of the medium and the resulting changes in osmolarity, relative humidity needs to be kept at nearly $100 \%$. Typically, $\mathrm{CO}_{2}$ gas is bubbled through a water container to humidify the incubator (Frigault et al. 2009). As fluorescence excitation induces ROS production (photodamage), it is quintessential to minimize light exposure, especially when aiming at quantification of intracellular ROS and redox-related processes (Dixit and Cyr 2003; Pattison and Davies 2006; Zhao et al. 2008). The most straightforward way to mitigate photodamage is to reduce the illumination load. This can be achieved by limiting the total imaging duration, but this goes at the expense of the signal-to-noise ratio. Hence, the efficiency of light collection should be optimized as well. 
This can be done using hard-coated filters, high numerical aperture (NA) lenses and detectors with high quantum efficiency, such as EM-CCD cameras (Frigault et al. 2009). When scaling a microscopy assay up to a multi-well format, variations in focus levels within and between wells impose another level of complexity. Images need to be perfectly focused to measure morphological and intensity metrics accurately (Koopman et al. 2008). Stage movements and time-resolved revisiting of regions of interest therefore call for accurate autofocusing methods. Hardware-based autofocusing methods, which rely on laser or LED deflection on the substrate, allow for continuous, real-time correction of the distance drifts between objective and substrate caused by plate imperfections and thermal fluctuations, while software-based methods correct for biological focus variations such as cell and organelle (e.g. mitochondria) positioning by calculating a sharpness or contrast metric in a series of axial recordings (Rabut and Ellenberg 2004; Frigault et al. 2009). Software-based autofocus methods are not recommended for redox biology imaging, because they require multiple exposures, but sometimes they are crucial to fine-tune hardware-driven axial positioning. To minimize phototoxicity, software-based autofocusing should be done using low intensity transmitted light. Another consideration when scaling up to a multi-well format is the time needed for the acquisition of all wells. The measured signal should be stable from the measurement of the first well to the last, but the total acquisition time increases linearly with the number of wells and the number of individual images recorded in each well. The available time window is dependent on several variables, including the dynamics of the process under investigation and the used staining method (for instance, transient staining with a small molecule dye versus stable expression of a genetic marker). 


\section{Method for simultaneous quantification of ROS levels and mitochondrial morphofunction}

Taking into account the considerations for microscopic assessment of redox biology, we have established a method for the simultaneous quantification of ROS levels and mitochondrial features in living cells using automated wide-field fluorescence microscopy and automated image analyses. The method is optimal for primary human dermal fibroblasts, which, due to their extremely flat morphology and relatively large size are well suited for analysis by widefield (non-confocal) fluorescence microscopy (Koopman et al. 2006). Nevertheless, the method should be applicable to a wide variety of adherent cell types. As proof-of-principle, we have chosen two generic and easily applicable fluorescent indicators, namely CM$\mathrm{H}_{2}$ DCFDA for measuring general intracellular ROS levels and TMRM for mitochondrial morphology and $\Delta \psi_{\mathrm{m}}$. An overview of the workflow is given in figure 3 .

\section{Sample preparation and image acquisition}

To make the assay amenable to medium- to high-throughput screens, we have optimized a workflow for 96-well plates. To minimize artifacts, cells are seeded at least 24 hours in advance and they are allowed to grow and equilibrate in conditioned medium. When using different conditions (e.g. controls and perturbations), seeding locations are homogeneously distributed so as to minimize plate effects. The outer wells are filled with medium, but are not imaged, as they are highly prone to edge effects. To avoid scattering and crosstalk (of excitation and emission) between adjacent wells, we make use of black polystyrene plates with a thin continuous polystyrene film bottom $\left(190 \mu \mathrm{m}+/-20 \mu \mathrm{m}\right.$; Greiner $\left.{ }^{\mathbb{R}}\right)$. A staining protocol was optimized that uses the/a? minimal amount of reporter dyes as overloading may affect cellular health status and cause non-linear effects due to quenching (Invitrogen 2006). Image acquisition is performed with an automated wide-field microscope using a $20 \mathrm{x}$ air plane?-corrected objective (NA $=0.75)$. The first well is sacrificed for determination of the optimal focus plane. As this procedure induces an increase in DCF signal intensity, this well is excluded from further analysis. Next, an acquisition protocol is initialized, using hardware based autofocus that captures a set of 4 fields per channel in the center of each well. With our setup, the plate acquisition time of this protocol is approximately 10 minutes. This has proven to be sufficiently short so as to not cause any significant differences between the first and last wells due to the transient nature of the staining or the dynamics of the processes under investigation. Optimization experiments revealed that both the DCFDA and TMRM signals remain stable from 7 to at least 50 minutes after loading (coefficient of variation $<2 \%$ ), allowing for a possible upscaling of the assay to 384-well plates.

After the acquisition protocol is completed, a stimulus/perturbation can be given, using an on- or off-stage automated micropipette or multichannel pipette. We make use of the oxidant tert-butyl peroxide (TBHP), as an internal positive control for the $\mathrm{CM}-\mathrm{H}_{2} \mathrm{DCFDA}$ staining, and as a means to measure induced ROS levels. At a fixed time span after TBHP addition (minimum 3 minutes to allow equilibration), the acquisition protocol is repeated. A maximum of 10 different treatments is used per plate. Then each plate contains 6 technical replicates with 4 images per replicate. In addition, a minimum of 3 identical plates is measured, increasing the number of images per treatment to a minimum of 72. This guarantees sufficient statistical power to detect even small differences.

\section{Image processing and data analysis}

After acquisition, raw image data sets are directly backed up to a server, with remote access. A virtual desktop application or command shell interface can be used to organize and analyze image data sets. All image processing is performed in FIJI (http://fiji.sc), a packaged version 
of ImageJ freeware (W.S. Rasband et al., National Institutes of Health, Bethesda, Maryland, USA, http://rsb.info.nih.gov/ij/, 1997-2015), which runs directly on the server. We have conceived a dedicated script for automated analysis of intracellular and mitochondrial signals and morphological characteristics (RedoxMetrics.ijm), which is available upon request. The image analysis pipeline can be divided into 4 major blocks, which can be adapted to the specific image quality and cell type, namely 1) preprocessing, 2) object enhancement, 3) segmentation, and 4) analysis (Fig 4).

1) Preprocessing is generic to all channels and involves a flatfield correction (FF) to correct for spatiotemporal illumination heterogeneity, which arises from imperfections of the acquisition system. The flat field image is usually acquired separately in a separate (usually outer) well with no cells, but with dyes. Alternatively, a pseudo-flatfield image is generated by means of an anisotropic 3D median filter, across all images of a well plate. Obviously this procedure only works well when there are sufficient images to average across (min. 50).

2) After preprocessing, the objects of interest will be selectively enhanced. Depending on the object, cells (CMDCFDA stains the entire cell) or mitochondria, different enhancement procedures are followed. For cell segmentation, a combination of local background subtraction (rolling ball, RB), noise reduction (in the form of a Gaussian blur operation, GB), and local contrast enhancement (CE) (Zuiderveld 1994) is used. The kernel sizes for these operators are tunable parameters, which are automatically set to optimized values based on the image calibration (pixel size), retrieved from the metadata. In case of mitochondria, a normalized Laplace of Gaussian operator (LG) is applied, for which the optimal scale is automatically selected based on the most salient features in scale space (De Vos et al. 2010). 3) Automatic segmentation demands implementation of a robust thresholding method. A variety of auto-threshold methods have been conceived (Sahoo et al. 1988; Glasbey 1993), and we have found Huang's algorithm (Huang and Wang 1995), which minimizes image fuzziness (the difference between the original image and its binary version), to work particularly well for both object types. However, an inherent caveat of auto-threshold methods is that they adjust the cut-off values based on the intensity distribution within the image. This introduces an unwanted bias when aiming at comparative quantifications, which is why we calculate threshold values using intensity information from the entire image data set. Alternatively, the threshold value can be set manually. Before proceeding to image analysis, a binary size filter (SF) is applied so as to exclude objects that fall out of the realistic size range.

4) Once generated, regions of Interest (ROIs) are used for extracting intensity, texture and morphological (size and shape) parameters on the flatfield corrected images. Both ROI sets are used to analyze signals in both channels, enabling spatial discrimination of intensity fluctuations.

\section{Data analysis and visualization}

Data analysis and visualization is done with R statistical freeware (http://www.r-project.org). Raw output from the image analysis is read in, together with the plate layout information, and is automatically organized and visualized. Intuitive heat maps, projected onto the original well-plate layout, allow for facile recognition of expected (e.g. dose-response) or unwanted (gradient) patterns and outliers (Fig. 3). The latter are usually automatically discarded (cf. gray wells in Fig. 3), based on quality criteria including minimal cell density or maximum intensity levels. Finally, intensity from the complete experiment is summarized and statistically compared.

\section{Validation}


To validate the described workflow, several control experiments have been conducted (Fig. 5). To verify the correlation between intracellular ROS levels and DCF fluorescence, and to determine its dynamic range, human fibroblasts were treated for 15 minutes with increasing concentrations of TBHP before being measured. Within a dose range of 10-160 $\mu \mathrm{M}$ TBHP, a linear correlation between ROS level and fluorescent signal was observed (Fig 5C). The same experimental setup was used for TMRM. Fibroblasts were treated for 30 minutes with increasing concentrations of oligomycin, which induces $\Delta \psi_{\mathrm{m}}$ hyperpolarization, before being measured. This approach equally resulted in a linear increase of the measured signal within the $1-10 \mu \mathrm{g} / \mu \mathrm{l}$ dose range (Fig 5A). Conversely, when fibroblasts were treated with valinomycin in fluxo, a gradual, quantifiable decrease of TMRM fluorescence was measured, corresponding to an expected $\Delta \psi_{\mathrm{m}}$ depolarization(Fig 5B). We also compared the microscopy-based method with spectrophotometry and flow cytometry (Fig. 5D). Flow cytometry showed a higher dynamic range (as measured after treatment with $20 \mu \mathrm{M}$ TBHP), but also a much larger variability in measurements (also note that this method requires the cells to be in suspension and does not allow for spatiotemporal analysis). Spectrophotometry showed a comparable dynamic range and variability. However, this method, just like flow cytometry, cannot discern morphological details nor is it capable of detecting confounding factors such as abnormal cell density or autofluorescent contaminants in individual wells.

Finally, we validated the generic character of the methodology by replacing the dye combinations $\mathrm{CM}-\mathrm{H}_{2}$ DCFDA/TMRM for Calcein/MitoSOX. Here, Calcein $(1 \mu \mathrm{M})$ was used to generate cell masks and to exclude dead cells from the analysis, MitoSOX $(5 \mu \mathrm{M})$ served to measure mitochondrial $\mathrm{O}_{2}{ }^{--}$levels. After staining, primary human fibroblasts were imaged at 1 frame each 6s. Addition of $500 \mu \mathrm{M}$ TBHP resulted in a clear increase of the MitoSOX signal, when measured per cellular pixel and even more pronounced when expressed per mitochondrial pixel (Fig. 6).

\section{Biological Applications}

After optimization and validation, we have performed a number of experiments to illustrate the performance of the high-content microscopy methodology. HIV protease inhibitors (HIV PI) have been shown to induce increased basal ROS levels (Chandra et al. 2009; Touzet and Philips 2010), and lowered antioxidant defenses (represented by lowered expression of SOD2 (Xiang et al. 2015)). Independently, other reports have linked HIV PI to changed mitochondrial morphofunction (Estaquier et al. 2002; Matarrese et al. 2003; Roumier et al. 2006; Bociąga-Jasik et al. 2013; Xiang et al. 2015). As a case study, we have used the established workflow to assess the effect of HIV PI on both parameters. To this end, primary human fibroblast cells were treated for $72 \mathrm{~h}$ with $20 \mu \mathrm{M}$ of the HIV PI Saquinavir (SQV experiment performed in biological triplicate). Subsequently, intracellular basal ROS levels, induced ROS levels, mitochondrial morphology and $\Delta \psi_{\mathrm{m}}$ were measured. Basal ROS levels were significantly higher compared to control cells treated with DMSO (Fig. 7A). Also the induced ROS levels were increased, pointing to lowered antioxidant defenses (Fig. 7B). With respect to the mitochondria, SQV treatment induced a highly fragmented phenotype when compared to control cells, illustrated by a higher circularity and lower average size of the individual mitochondria (Fig. 7D). $\Delta \psi_{\mathrm{m}}$, measured as average TMRM signal per mitochondrial pixel, was not significantly altered (not shown). Using the dye combination Calcein/MitoSOX, we also quantified mitochondrial $\mathrm{O}_{2}{ }^{--}$levels. When applied to fibroblasts, treated for $72 \mathrm{~h}$ with $10 \mu \mathrm{M}$ of SQV, we measured a significant increase in mitochondrial $\mathrm{O}_{2}{ }^{\circ}$ levels compared to control cells treated with DMSO (Fig. 7C). A specific increase in this localized ROS variant aligns well with earlier findings showing that SQV induces lower expression of the mitochondrial enzyme SOD2 (Xiang et al. 2015). 
Our multiparametric analysis yielded a feature set describing both morphological and intensity characteristics. When performing a principal component analysis (PCA) using a subset of 5 parameters, namely basal and induced ROS levels, average mitochondrial size, average mitochondrial circularity and $\Delta \psi_{\mathrm{m}}$, we could unambiguously separate the two conditions (control and SQV-treated) independently in three biological replicates with just the first two principal components, explaining $81.4 \%$ of the total variance in the data (Fig. 8A). This demonstrates the robustness of our workflow and suggests that the combined readout may serve as a sensitive predictor of cellular health condition. To test this hypothesis we ran a similar analysis on a group of laminopathy patient cells, for which we have previously shown differential ROS levels and mitochondrial dysfunction (Sieprath et al. 2015). Specifically, we compared fibroblasts from a healthy patient, with those from a patient suffering from Hutchinson-Gilford Progeria (G608G/+) (Verstraeten et al. 2006) and fibroblasts from a patient with a lethal laminopathy phenotype due to a nonsense Y259X homozygous mutation in the LMNA gene (Y259X/Y259X) (Muchir et al. 2003). Again, using only 5 variables and 2 PCs, all three cell types could be readily separated (Fig. 8B). 


\section{Discussion}

In this work, we have described and benchmarked a workflow for simultaneous quantification of intracellular ROS levels and mitochondrial morphofunction. As proof-ofprinciple, we showed that SQV induces a significant rise in basal as well as induced ROS levels in human fibroblasts, and that this is accompanied by distinct mitochondrial fragmentation as well as increased mitochondrial $\mathrm{O}_{2}{ }^{-}$levels. These findings support earlier evidence in the literature where increased ROS levels or mitochondrial dysfunction were also observed individually upon treatment with type 1 HIV protease inhibitors (Estaquier et al. 2002; Matarrese et al. 2003; Roumier et al. 2006; Chandra et al. 2009; Touzet and Philips 2010; Bociąga-Jasik et al. 2013; Xiang et al. 2015), but it is the first time these parameters were measured simultaneously. The major advantage is that an unambiguous determination of both factors together in space and time allows pinpointing causal relationships. For instance, by including compounds that promote or reduce mitochondrial function (ETC) or dynamics (fusion/fission), one could now directly assess the impact on intracellular ROS levels and vice versa. Another advantage of our method lies in its generic character in a sense that virtually any combination of spectrally compatible fluorescent probes for ROS and mitochondria can be used (as demonstrated by the use of MitoSOX to measure mitochondrial $\mathrm{O}_{2}{ }^{-}$levels). It is becoming increasingly clear that, besides the general cell-wide effects of ROS, fast, transient and highly localized production of low doses of specific intracellular ROS species plays an important role in cellular signal transduction and mitochondrial morphofunction. We have previously used the Calcein/MitoSOX approach to study (mitochondrial) $\mathrm{O}_{2}{ }^{-}$levels in human fibroblast cells with LMNA and ZMPSTE24 knockdowns (Sieprath et al. 2015). However, any targetable ROS probe that has fast equilibration kinetics could be used. It is in this field that great progress is conceivable. As yet, not many such sensors exist. HyPer and (Orp1)roGFP2 would be good candidates, but their kinetics would still have to be improved to be able to really measure quick transient changes. In extensu, the workflow is easily amenable to the analysis of other organelles (e.g. the ER) and while the method was originally conceived for cell-based assays, it has already been adapted to cater for measurements of redox metabolism and mitochondrial morphology or density in C. elegans (Back et al. 2012; Castelein et al. 2014; de Boer et al. 2015; Smith et al. 2015). Despite proven performance in $2 \mathrm{D}$, a challenge resides in the $3 \mathrm{D}$ nature of the imaged tissue, demanding confocal instead of widefield acquisition and more complex 3D segmentation procedures.

While being measured simultaneously, processing and analysis of the redox and mitochondrial parameters is usually done separately to gain unbiased insight into the fundamental underlying processes. However, integration of all the information using data mining techniques allows the calculation of more sensitive fingerprints. In line with this, we have shown that both chemically (SQV) treated cells and laminopathy patient cells could become effectively discriminated using a combination of 5 different metrics. Such a redox fingerprint may become a valuable tool for classification of cells from different pathological conditions or could lead to novel cell-based screening methods for diagnostic purposes. It has been shown that the combination of multiple morphological parameters of the mitochondrial network permits robust classification of different phenotypes using unsupervised as well as supervised data mining strategies (de Boer et al. 2015; Blanchet et al. 2015). Indeed, hierarchical clustering has allowed for stratifying antiretroviral drug treatments based on mitochondrial morphology fingerprints (de Boer et al. 2015). Likewise, learning methods (logistic regression and support vector machines learning) have been successfully used to discriminate between primary fibroblasts of a healthy individual and a Leigh Syndrome patient and to identify potential therapeutic compounds based on their mitochondrial morpho- 
functional phenotype (Blanchet et al. 2015). These examples demonstrate the potential of integrated image-based redox profiling.

In conclusion, we believe that our method will contribute to a better understanding of the relationship between mitochondrial function and intracellular ROS signaling. This, in turn, will provide invaluable information regarding a wide variety of human pathologies in which mitochondrial function and redox homeostasis are disturbed.

\section{Acknowledgements}

This research was supported by the University of Antwerp (TTBOF/UA_29267), the Special Research Fund of Ghent University (project BOF/11267/09), the Hercules foundation (AUGE/ 013), NB-Photonics (Project code 01-MR0110) and the CSBR (Centers for Systems Biology Research) initiative from the Netherlands Organization for Scientific Research (NWO; No: CSBR09/013V). 


\section{Figures}

A

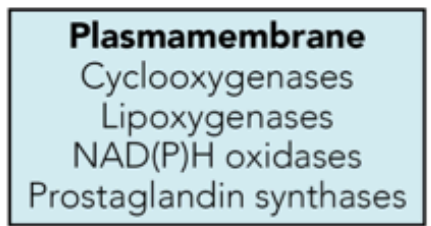

Cytoplasm

Catecholamines

Riboflavin

Xanthine oxidase

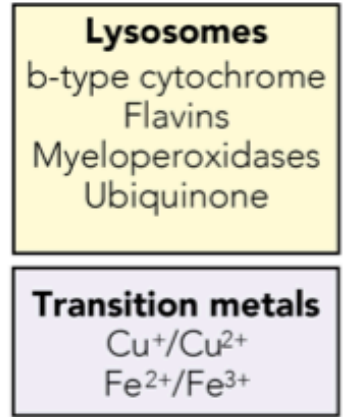

ER/microsomes

Cyt-b5

Cyt-P450

Nox4

Exogenous

pollutan

Drugs

$\gamma$-radiation

Oxidants

Smoke

UV radiation
Peroxisomes

Oxidases

Peroxidases

Flavoproteins

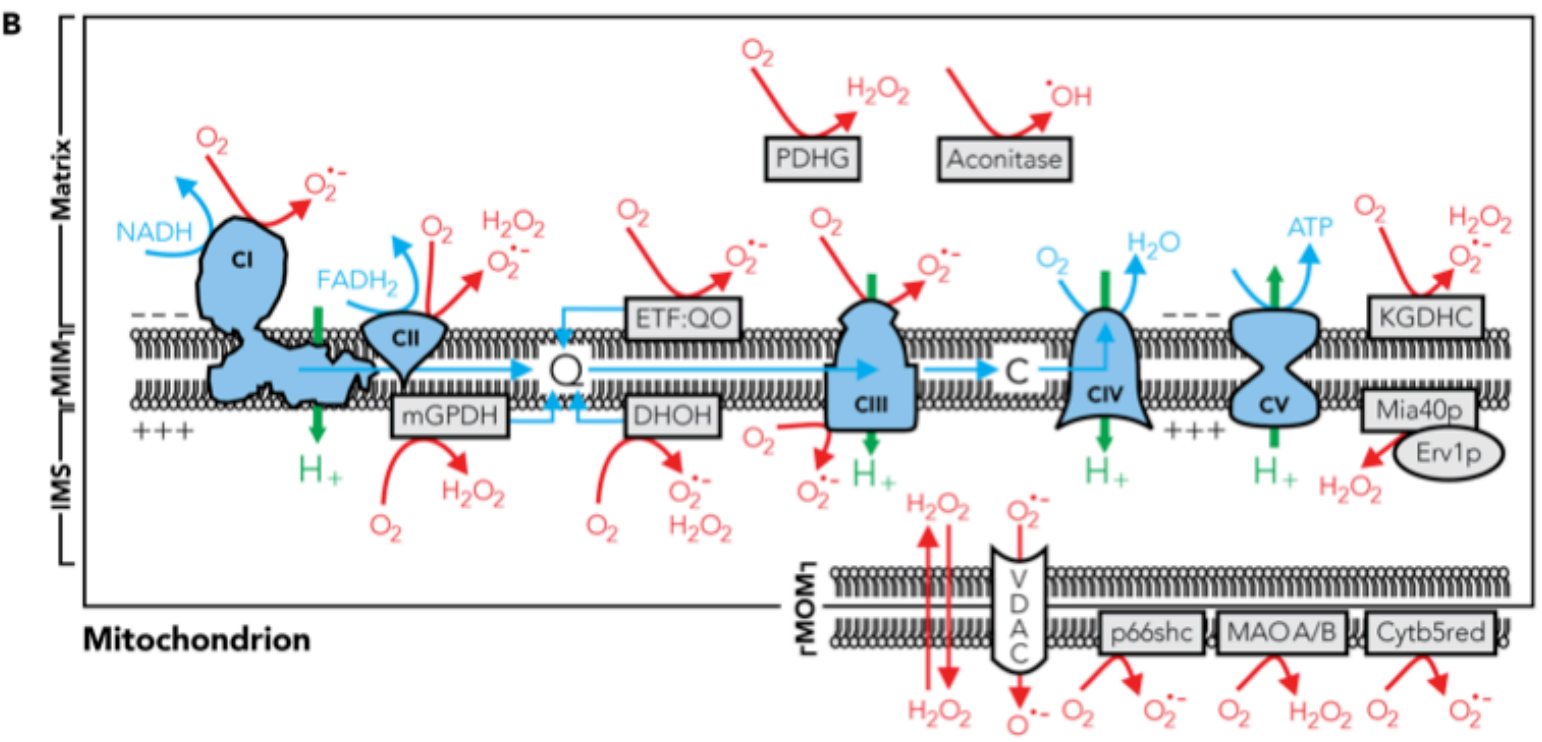

Figure 1: Cellular sources of reactive oxygen species. (A) Non-mitochondrial sources of reactive oxygen species. (B) Mitochondrial sources of $\mathrm{O}_{2}{ }^{-}$and $\mathrm{H}_{2} \mathrm{O}_{2}$. The scheme depicts the five complexes of the mitochondrial oxidative phosphorylation system involved in ATP production (CI-CV; blue) and other mitochondrial ROS-generating proteins (grey boxes). Once formed, the anionic $\mathrm{O}_{2}{ }^{--}$cannot move across membranes, whereas $\mathrm{H}_{2} \mathrm{O}_{2}$ can more freely diffuse. Abbreviations: Cytb5red, cytochrome b5 reductase; DHOH, dihydroorotate dehydrogenase; Erv1p/Mia40p, redox system that forms disulfide bridges on proteins to be imported by mitochondria; ETF:QO, electron transfer flavoprotein-ubiquinone oxidoreductase; KGDHC, $\alpha$-ketoglutarate dehydrogenase complex; MAO, monoamine oxidase; mGPDH, mitochondrial glycerol-3-phosphate dehydrogenase; p66shc, 66-kDa src collagen homologue (shc) adaptor protein; PDHG, pyruvate dehydrogenase complex; VDAC, voltage-dependent anion channel. The data for this figure was compiled from: (Giustarini et al. 2009; Koopman et al. 2010; Marchi et al. 2012; Brown and Borutaite 2012; Nathan and Cunningham-Bussel 2013; Woolley et al. 2013; Mailloux et al. 2013) 

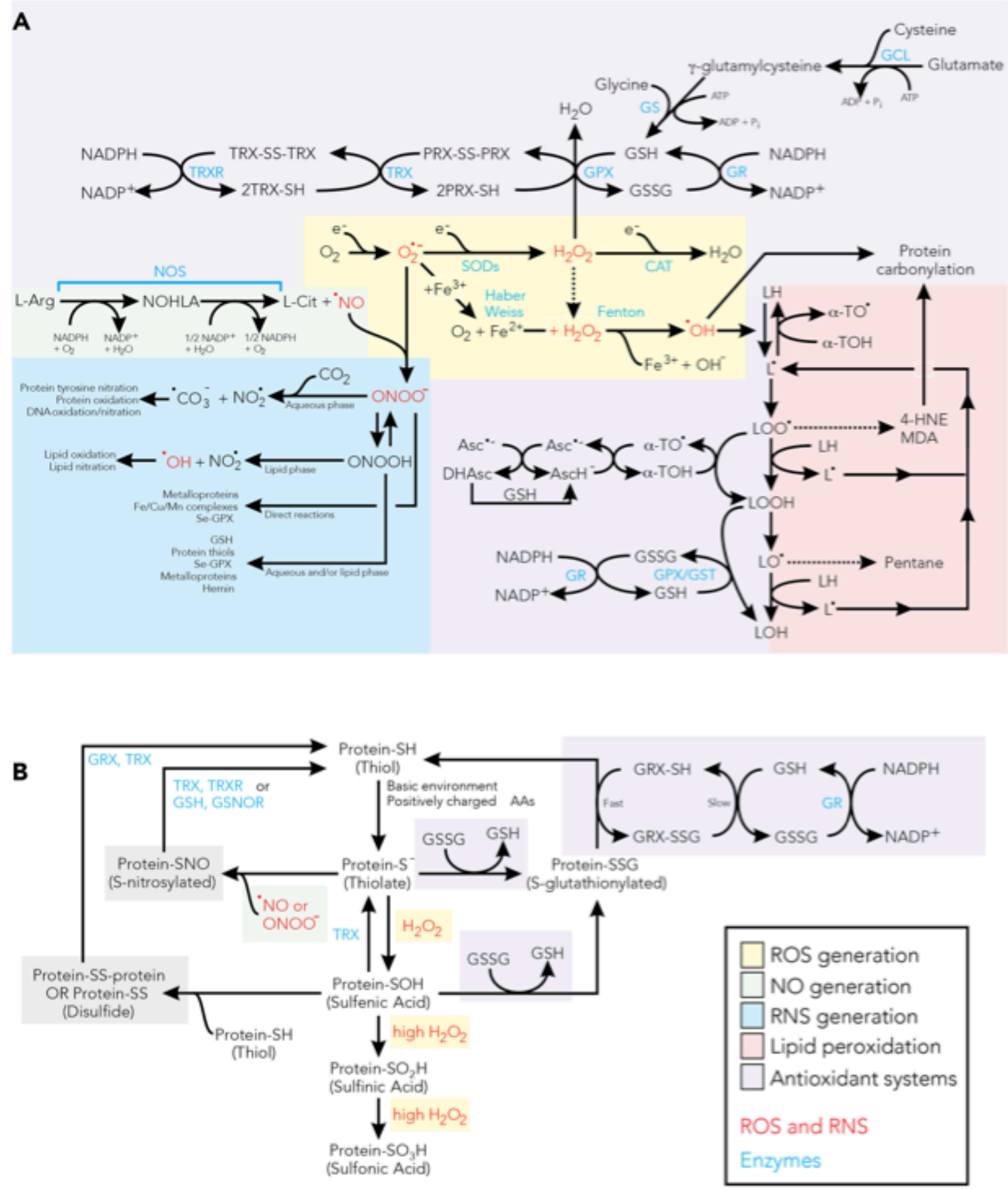

Figure 2: Redox homeostasis in mammalian cells. (A) Formation of ROS and NO/RNS, their removal by antioxidant systems and role in lipid peroxidation. (B) Reactions of protein thiol (protein-SH) groups leading to reversible S-nitrosilation (protein-SNO), intra or inter-protein disulfide bond formation (SS) or S-glutationylation (protein-SSG). Abbreviations: 4-HNE, 4-hydroxynonenal; $\alpha$-TOH, $\alpha$-tocopherol; $\alpha$-TO', $\alpha$-tocopherol radical; Asc ${ }^{\circ-}$, ascorbyl radical; AscH', ascorbate; CAT, catalase; GCL, glutamate cysteine ligase; GPX, glutathione peroxidase; GR, glutathione reductase; GS, glutathione synthase; GSH, glutathione; GSNOR, S-nitrosoglutathione reductase; GSSG, oxidized glutathione; MDA, malondialdehyde; NADPH, reduced nicotinamide adenine dinucleotide phosphate; NOS, nitric oxide synthase; NOHLA, N $\omega$-hydroxy-L-arginine; PRX, peroxiredoxin; RNS, reactive nitrogen species; ROS, reactive oxygen species; SOD, superoxide dismutase; TRX, 
thioredoxin; TRXR, thioredoxin reductase. The data for this figure was compiled from: (Auchère and Rusnak 2002; Szabó et al. 2007; Sachdev and Davies 2008; Benhar et al. 2009; Rasmussen et al. 2010; Finkel 2011; Traber and Stevens 2011; Pastore and Piemonte 2012; Marí et al. 2013; Nathan and Cunningham-Bussel 2013; Saaranen and Ruddock 2013; Conte and Carroll 2013; Cremers and Jakob 2013; Stangherlin and Reddy 2013; Mailloux et al. 2013; Groitl and Jakob 2014) 
A

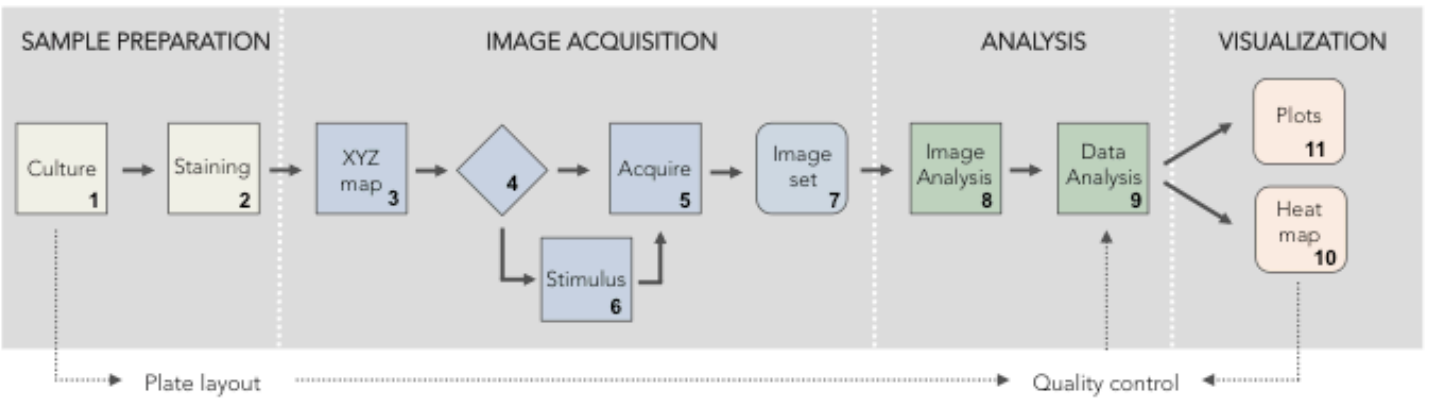

B

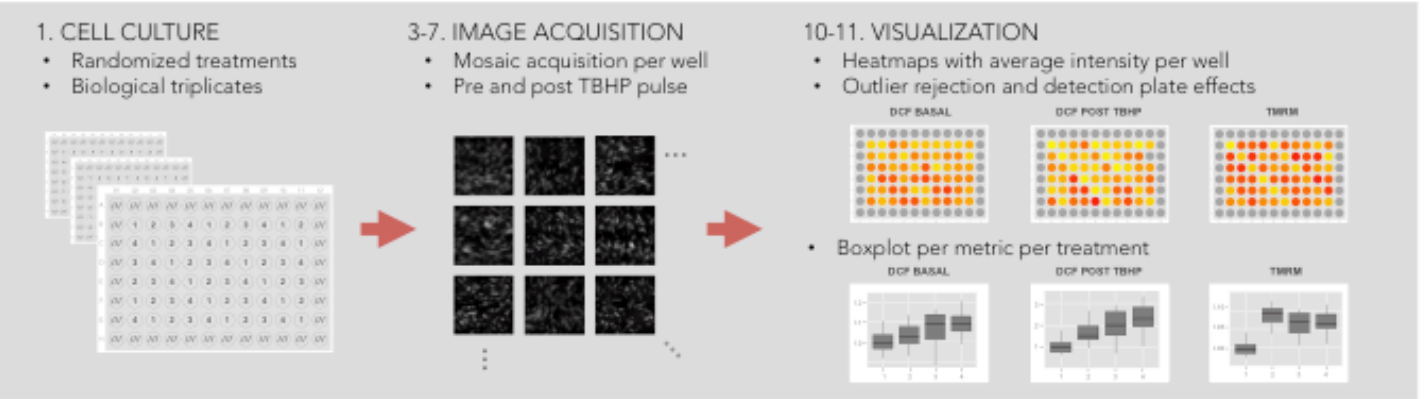

Figure 3: General overview of the high-content method for simultaneous measurement of intracellular basal and induced ROS levels and mitochondrial morphofunction. (A) Schematic representation of the major operational blocks and subtasks. (B) Illustrated example: Cells are seeded in multiple identical 96-well plates. The numbers in the wells represent different treatments, homogeneously distributed along the plate. After staining, 4 images are taken per channel in the center of each well, both pre and post in fluxo treatment. The image analysis workflow is described in more detail in figure 4. Intuitive representation of the intensity results in a 96-well layout permits rapid detection of plate effects (plate-wide gradient patterns - as seen in the DCF basal image) or aberrant wells. After curation of complete experimental data sets, data analysis is performed. 
A

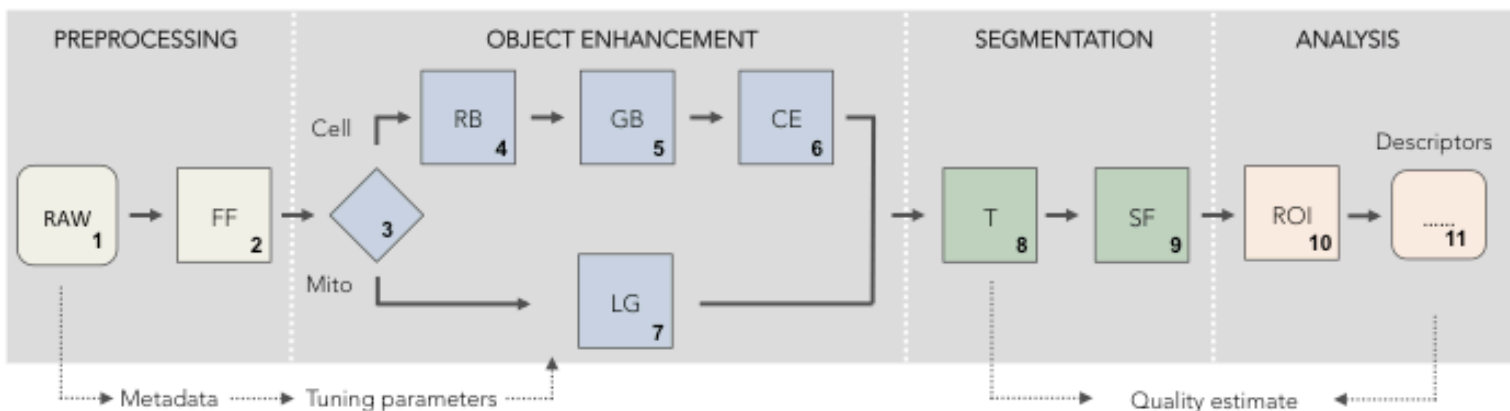

B

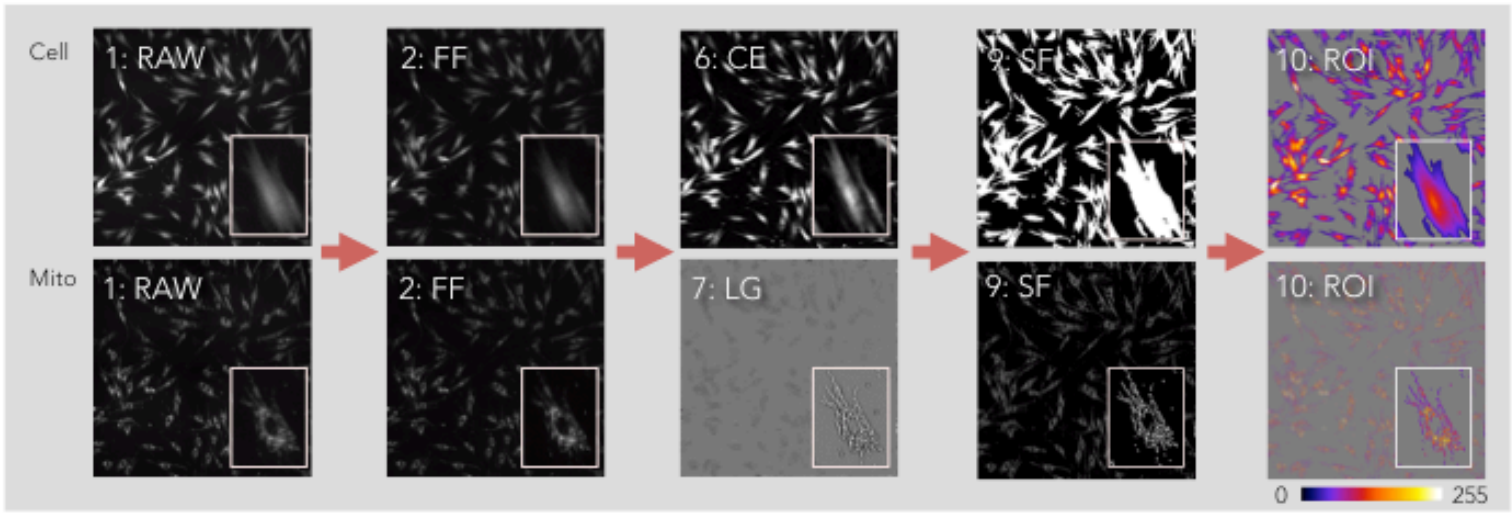

Figure 4: Overview of the image analysis workflow. (A) Schematic representation of the entire image analysis process. Abbreviations: FF - Flatfield correction, RB - Rolling ball background subtraction, GB - Gaussian blur, CE - Local Contrast enhancement, LG Laplace of Gaussian, T - Thresholding, SF - Size filter, ROI - Region of interest. (B) Illustrated example. The top row represents the analysis of DCF images, the bottom row the analysis of TMRM images. 

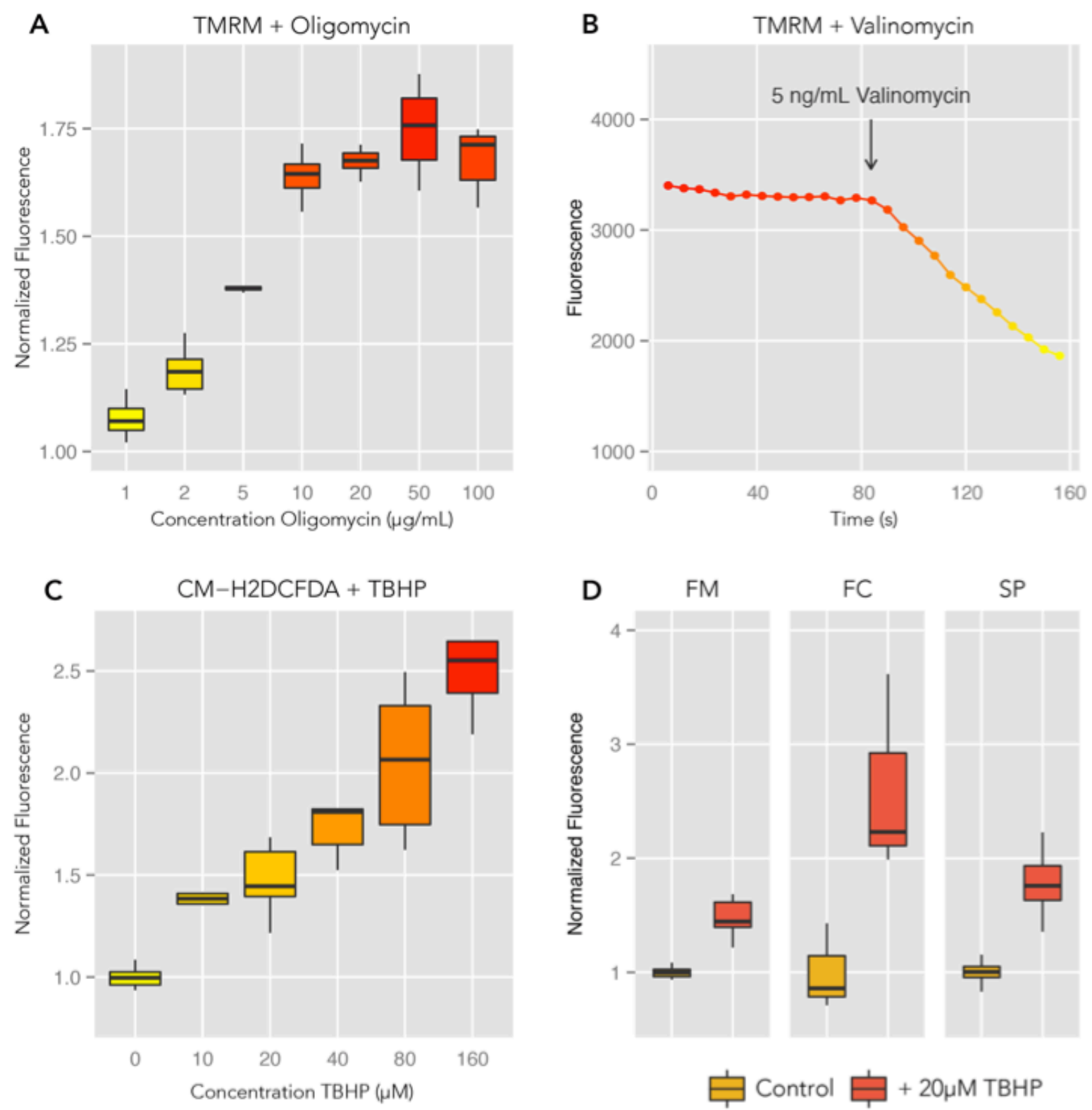

Figure 5: Validation of the CM- $\mathrm{H}_{2} \mathrm{DCFDA} / \mathrm{TMRM}$-based high content microscopy method. All experiments were conducted in primary human fibroblasts. (A) Normalized $\Delta \psi$ as measured by mitochondrial TMRM signal after treatment with increasing concentrations of oligomycin for 30 minutes. (B) Live cell imaging of $\Delta \psi$ in cells stained with TMRM and treated with $5 \mathrm{ng} / \mathrm{mL}$ valinomycin after $85 \mathrm{~s}$. (C) Normalized levels of intracellular ROS measured as intracellular $\mathrm{CM}-\mathrm{H}_{2}$ DCFDA signal after treatment with increasing concentrations of TBHP for 15 minutes. (D) Comparison of microscopic, flow cytometric and spectrophotometric (plate reader) measurement of basal intracellular ROS levels using $\mathrm{CM}-\mathrm{H}_{2}$ DCFDA in control cells (CTR) versus cells treated with $20 \mu \mathrm{M}$ TBHP. 

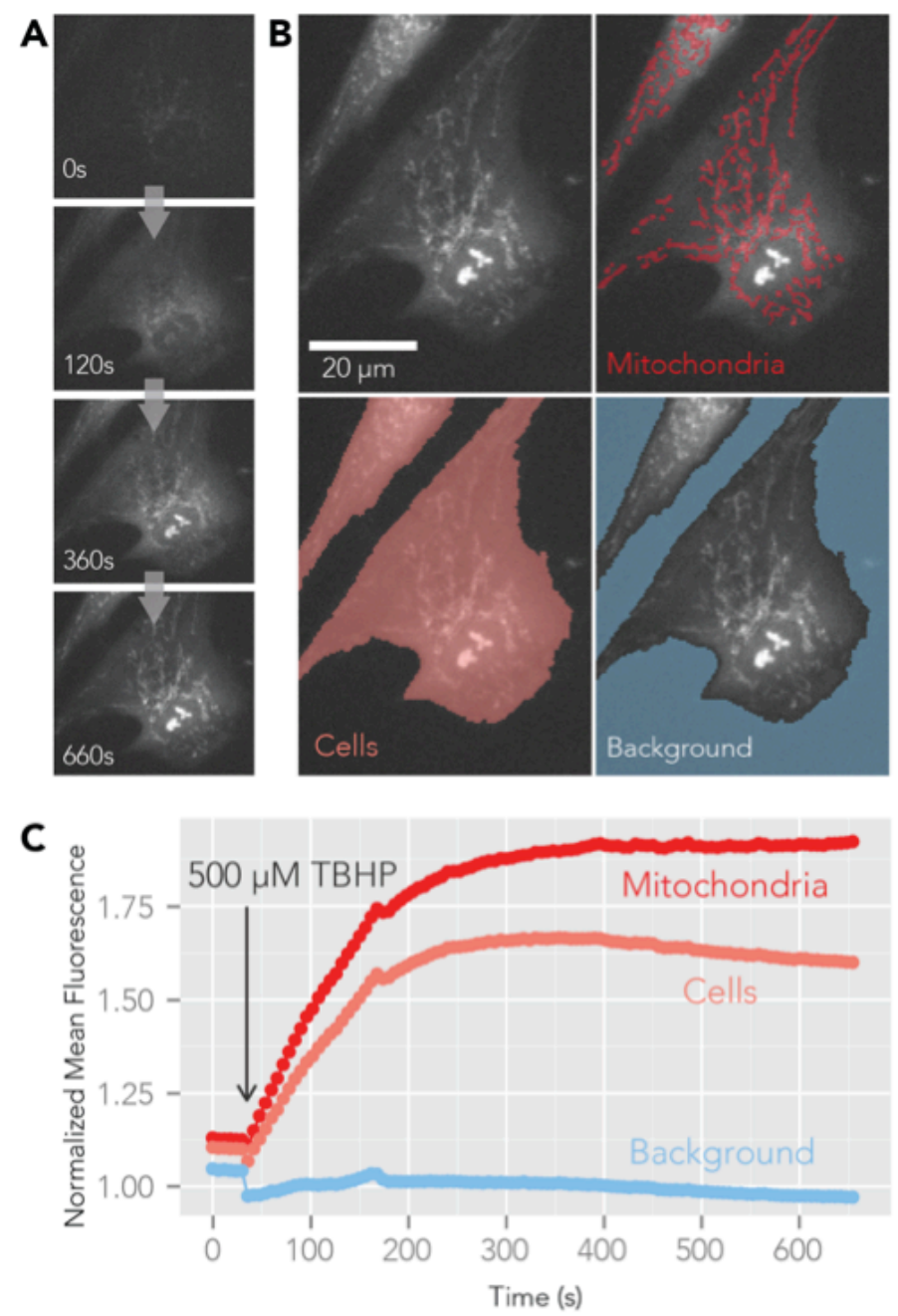

Figure 6: Compatibility of the HC assay with MitoSOX measurements. (A) response of cells stained with $5 \mu \mathrm{M}$ MitoSOX towards acute addition of $500 \mu \mathrm{M}$ TBHP. (B) Masks used to measure fluorescence intensity in different parts of the image. (C) Normalized mean fluorescence in function of time as measured through the different masks shown in (B). (The bump observed after approx. 160s is due to a floating fluorescent particle (probably a detached cell) passing, out of focus, through the field of view inducing a weak increase in signal in the affected images.) 

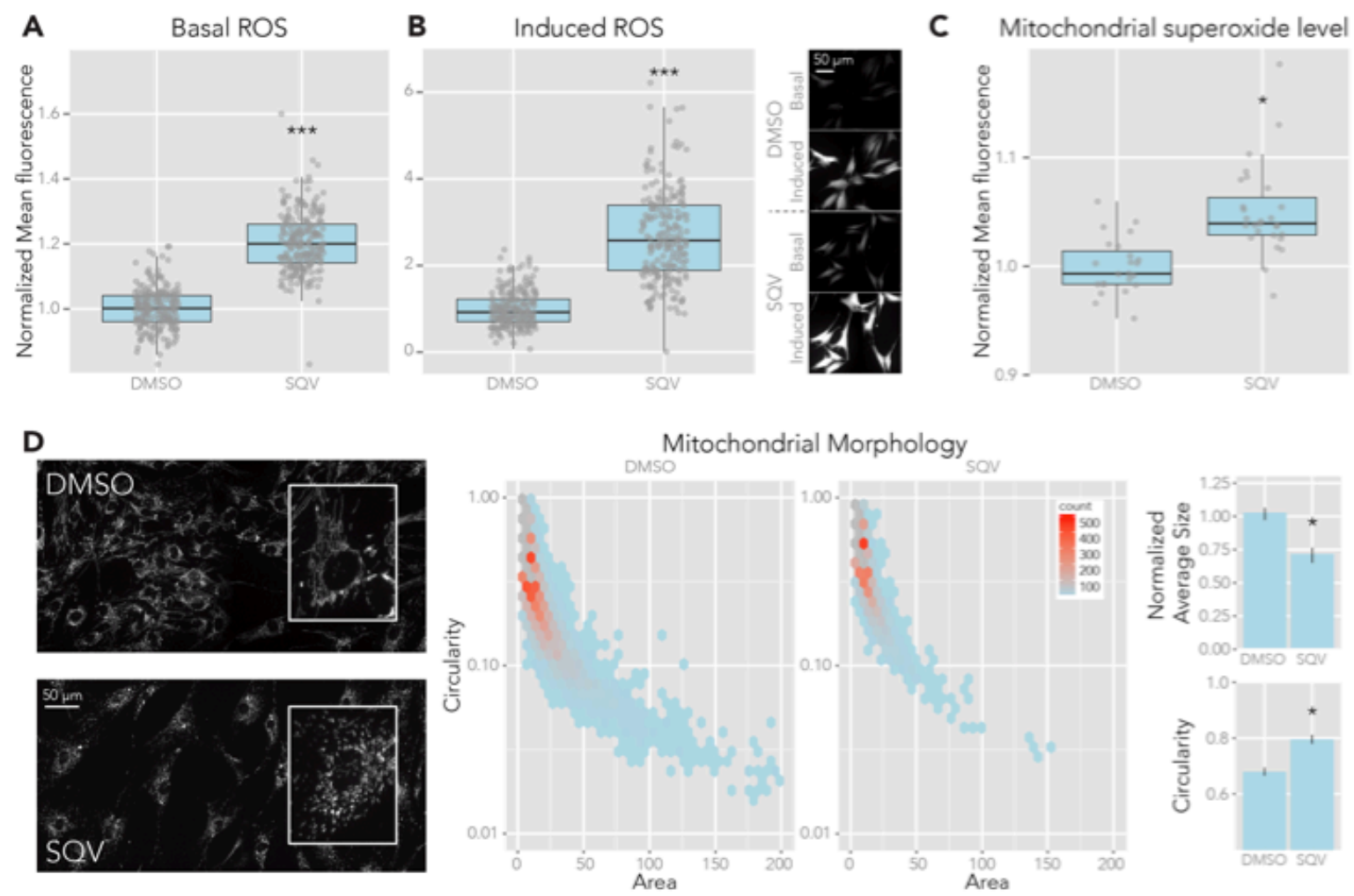

Figure 7: Effect of Saquinavir (SQV; HIV-1 protease inhibitor) on primary human fibroblasts (control is DMSO). (A) Normalized basal levels of intracellular ROS as measured by $\mathrm{CM}-\mathrm{H}_{2} \mathrm{DCFDA}$ and (B) response towards induced ROS, measured as relative gain in intensity after $20 \mathrm{mM}$ TBHP addition at different time points after treatment with $20 \mu \mathrm{M}$ of SQV. (C) Normalized $\mathrm{O}_{2} \bullet^{-}$level as measured by average MitoSOX signal per mitochondrial pixel after treatment with $10 \mu \mathrm{M}$ SQV. (D) SQV treatment $(20 \mu \mathrm{M})$ causes mitochondrial fragmentation as illustrated by (E) a scatterplot of mitochondrial circularity and mitochondrial area (D) $*^{*}=$ p-value $<0.05 ; * *=$-value $<0.01 ; * * *=p$-value $<0.001$; the range of the $\mathrm{Y}$-axes has been adjusted to optimally display the differences) 


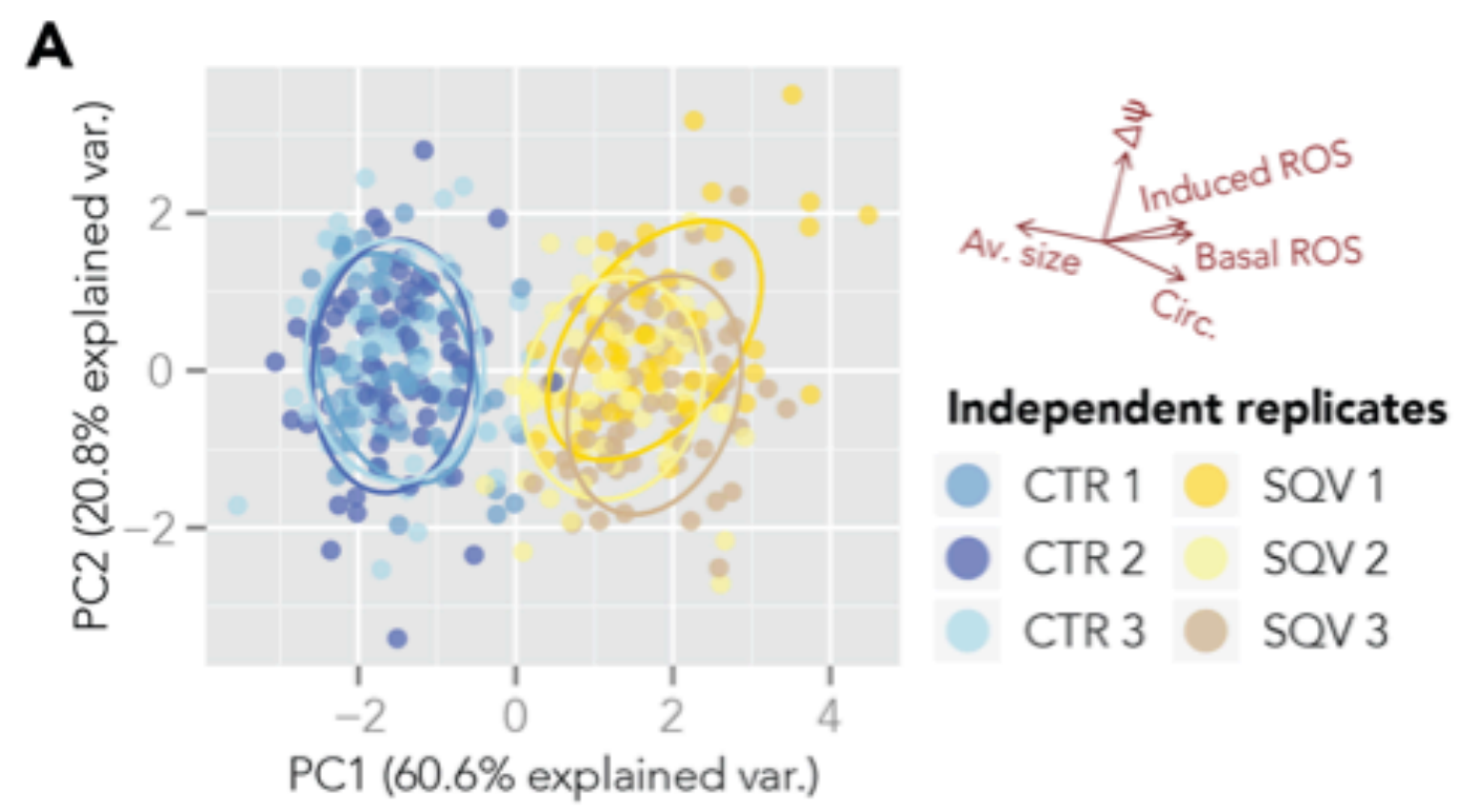

B
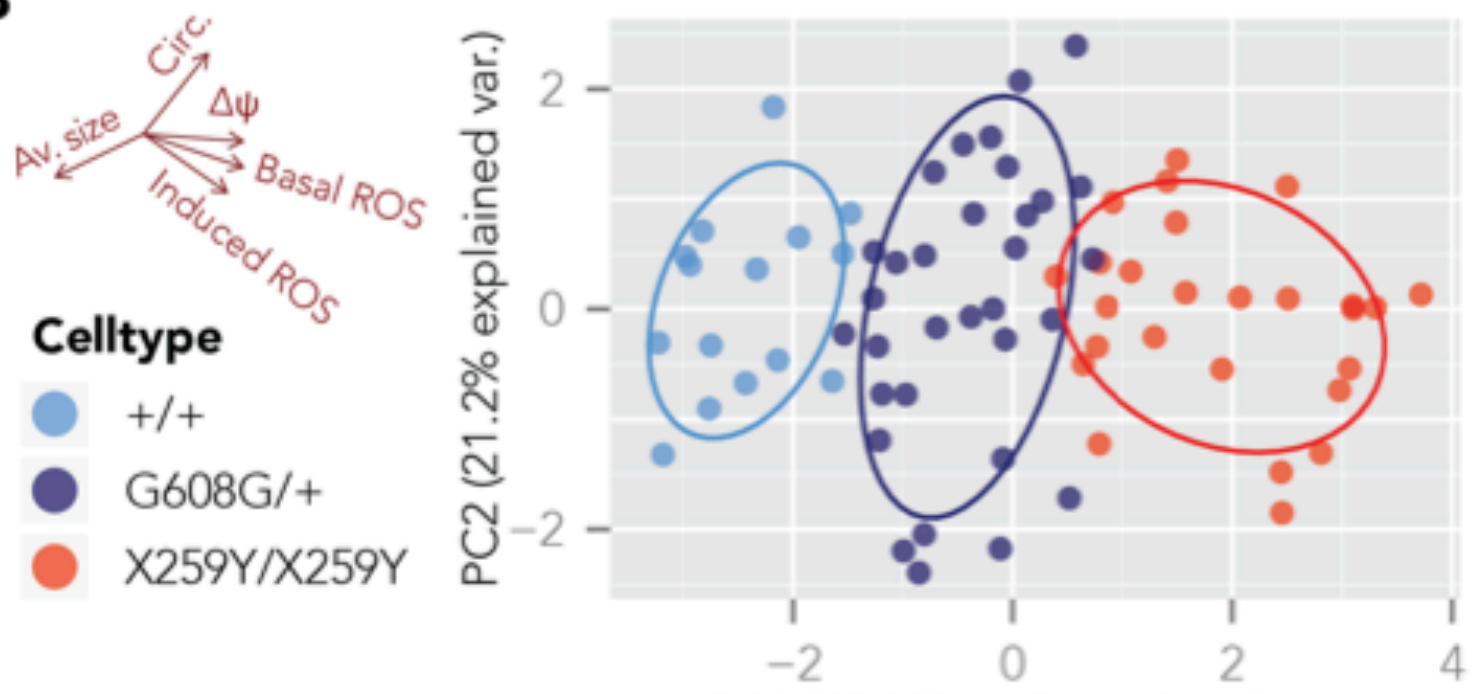

PC1 (63.8\% explained var.)

Figure 8: Principal component analysis (PCA) distinguishes chemically perturbed cells and patient cells from healthy controls. (A) 2D scatterplot of the first 2 principal components (PCs) from a PCA analysis on 5 variables (basal and induced ROS levels, average mitochondrial size, circularity and $\Delta \psi_{\mathrm{m}}$ ) from the SQV dataset described in fig. 7 . Independent replicates are plotted with a different color. The brown arrows represent the directions of the original 5 variables with respect to the principal components. (B) 2D scatterplot of the first 2 principal components (PCs) from a PCA analysis on the same 5 variables measured in 2 different laminopathy patient cell lines and healthy primary human fibroblasts. 


\section{References}

Archer SL (2013) Mitochondrial dynamics--mitochondrial fission and fusion in human diseases. N Engl J Med 369:2236-2251. doi: 10.1056/NEJMra1215233

Auchère F, Rusnak F (2002) What is the ultimate fate of superoxide anion in vivo? J Biol Inorg Chem 7:664-667. doi: 10.1007/s00775-002-0362-2

Babior B (1999) NADPH oxidase: An update. Blood 93:1464-1476.

Back P, De Vos WH, Depuydt GG, et al (2012) Free Radical Biology \& Medicine. Free Radical Biology and Medicine 52:850-859. doi: 10.1016/j.freeradbiomed.2011.11.037

Baird GS, Zacharias DA, Tsien RY (1999) Circular permutation and receptor insertion within green fluorescent proteins. P Natl Acad Sci Usa 96:11241-11246.

Bartz RR, Piantadosi CA (2010) Clinical review: oxygen as a signaling molecule. Crit Care 14:234. doi: $10.1186 / \mathrm{cc} 9185$

Bedard K, Krause K-H (2007) The NOX family of ROS-generating NADPH oxidases: Physiology and pathophysiology. Physiol Rev 87:245-313. doi:

10.1152/physrev.00044.2005

Belousov VV, Fradkov AF, Lukyanov KA, et al (2006) Genetically encoded fluorescent indicator for intracellular hydrogen peroxide. Nat Methods 3:281-286. doi: $10.1038 /$ nmeth 866

Benhar M, Forrester MT, Stamler JS (2009) Protein denitrosylation: enzymatic mechanisms and cellular functions. Nat Rev Mol Cell Biol 10:721-732. doi: 10.1038/nrm2764

Bilan DS, Pase L, Joosen L, et al (2013) HyPer-3: a genetically encoded H(2)O(2) probe with improved performance for ratiometric and fluorescence lifetime imaging. ACS Chem Biol 8:535-542. doi: 10.1021/cb300625g

Blanchet L, Smeitink JAM, van Emst-de Vries SE, et al (2015) Quantifying small molecule phenotypic effects using mitochondrial morpho-functional fingerprinting and machine learning. Sci Rep 5:8035. doi: 10.1038/srep08035

Bociąga-Jasik M, Polus A, Góralska J, et al (2013) Metabolic effects of the HIV protease inhibitor--saquinavir in differentiating human preadipocytes. Pharmacol Rep 65:937950.

Boveris A, Chance B (1973) The mitochondrial generation of hydrogen peroxide. General properties and effect of hyperbaric oxygen. Biochem J 134:707-716.

Boveris A, Valdez LB, Zaobornyj T, Bustamante J (2006) Mitochondrial metabolic states regulate nitric oxide and hydrogen peroxide diffusion to the cytosol. Biochim Biophys Acta 1757:535-542. doi: 10.1016/j.bbabio.2006.02.010

Brown GC, Borutaite V (2012) There is no evidence that mitochondria are the main source of reactive oxygen species in mammalian cells. Mitochondrion 12:1-4. doi:

10.1016/j.mito.2011.02.001 
Cardoso AR, Chausse B, da Cunha FM, et al (2012) Mitochondrial compartmentalization of redox processes. Free Radical Biology and Medicine 52:2201-2208. doi: 10.1016/j.freeradbiomed.2012.03.008

Caron M, Auclair M, Donadille B, et al (2007) Human lipodystrophies linked to mutations in A-type lamins and to HIV protease inhibitor therapy are both associated with prelamin A accumulation, oxidative stress and premature cellular senescence. Cell Death Differ 14:1759-1767. doi: 10.1038/sj.cdd.4402197

Casey JR (2006) Why bicarbonate? Biochem Cell Biol 84:930-939. doi: 10.1139/o06-184

Castelein N, Muschol M, Dhondt I, et al (2014) Experimental Gerontology. EXG 56:26-36. doi: 10.1016/j.exger.2014.02.009

Chandra S, Mondal D, Agrawal KC (2009) HIV-1 protease inhibitor induced oxidative stress suppresses glucose stimulated insulin release: protection with thymoquinone. Exp Biol Med (Maywood) 234:442-453. doi: 10.3181/0811-RM-317

Chang MCY, Pralle A, Isacoff EY, Chang CJ (2004) A selective, cell-permeable optical probe for hydrogen peroxide in living cells. J Am Chem Soc 126:15392-15393. doi: $10.1021 / \mathrm{ja} 0441716$

Chazotte B (2011) Labeling mitochondria with MitoTracker dyes. Cold Spring Harb Protoc 2011:990-992. doi: 10.1101/pdb.prot5648

Chen Z-H, Saito Y, Yoshida Y, et al (2005) 4-Hydroxynonenal induces adaptive response and enhances PC12 cell tolerance primarily through induction of thioredoxin reductase 1 via activation of Nrf2. J Biol Chem 280:41921-41927. doi: 10.1074/jbc.M508556200

Chiu C-C, Yeh T-H, Lai S-C, et al (2015) Neuroprotective effects of aldehyde dehydrogenase 2 activation in rotenone-induced cellular and animal models of parkinsonism. Exp Neurol 263:244-253. doi: 10.1016/j.expneurol.2014.09.016

Chouchani ET, Methner C, Nadtochiy SM, et al (2013) Cardioprotection by S-nitrosation of a cysteine switch on mitochondrial complex I. Nat Med 19:753-759. doi: doi:10.1038/nm.3212

Conte Lo M, Carroll KS (2013) The redox biochemistry of protein sulfenylation and sulfinylation. J Biol Chem 288:26480-26488. doi: 10.1074/jbc.R113.467738

Cremers CM, Jakob U (2013) Oxidant sensing by reversible disulfide bond formation. J Biol Chem 288:26489-26496. doi: 10.1074/jbc.R113.462929

de Boer R, Smith RL, De Vos WH, et al (2015) Caenorhabditis elegans as a Model System for Studying Drug Induced Mitochondrial Toxicity. PLoS ONE 10:e0126220. doi: 10.1371/journal.pone. 0126220

De Vos WH, Van Neste L, Dieriks B, et al (2010) High content image cytometry in the context of subnuclear organization. Cytometry A 77:64-75. doi: 10.1002/cyto.a.20807

Dickinson BC, Chang CJ (2011) Chemistry and biology of reactive oxygen species in signaling or stress responses. Nat Chem Biol 7:504-511. doi: doi:10.1038/nchembio.607 
Dickinson BC, Huynh C, Chang CJ (2010a) A Palette of Fluorescent Probes with Varying Emission Colors for Imaging Hydrogen Peroxide Signaling in Living Cells.

Dickinson BC, Lin VS, Chang CJ (2013) Preparation and use of MitoPY1 for imaging hydrogen peroxide in mitochondria of live cells. Nat Protoc 8:1249-1259. doi: 10.1038/nprot.2013.064

Dickinson BC, Srikun D, Chang CJ (2010b) Mitochondrial-targeted fluorescent probes for reactive oxygen species. Current Opinion in Chemical Biology 14:50-56. doi: 10.1016/j.cbpa.2009.10.014

Dikalov SI, Harrison DG (2014) Methods for detection of mitochondrial and cellular reactive oxygen species. Antioxidants \& Redox Signaling 20:372-382. doi:

10.1089/ars.2012.4886

Dixit R, Cyr R (2003) Cell damage and reactive oxygen species production induced by fluorescence microscopy: effect on mitosis and guidelines for non-invasive fluorescence microscopy. Plant J 36:280-290.

Dong H, Cheung SH, Liang Y, et al (2013) "Stainomics": identification of mitotracker labeled proteins in mammalian cells. Electrophoresis 34:1957-1964. doi: 10.1002/elps.201200557

Dooley CT, Dore TM, Hanson GT, et al (2004) Imaging Dynamic Redox Changes in Mammalian Cells with Green Fluorescent Protein Indicators. J Biol Chem 279:2228422293. doi: 10.1074/jbc.M312847200

Drummen GPC, van Liebergen LCM, Op den Kamp JAF, Post JA (2002) C11BODIPY581/591, an oxidation-sensitive fluorescent lipid peroxidation probe: (micro)spectroscopic characterization and validation of methodology. Free Radical Biology and Medicine 33:473-490. doi: 10.1016/S0891-5849(02)00848-1

Dupre-Crochet S, Erard M, Nusse O (2013) ROS production in phagocytes: why, when, and where? Journal of Leukocyte Biology 94:657-670. doi: 10.1189/jlb.1012544

Estaquier J, Lelièvre J-D, Petit F, et al (2002) Effects of antiretroviral drugs on human immunodeficiency virus type 1-induced CD4(+) T-cell death. J Virol 76:5966-5973.

Finkel T (2011) Signal transduction by reactive oxygen species. J Cell Biol 194:7-15. doi: $10.1083 /$ jcb.201102095

Forkink M, Willems PHGM, Koopman WJH, Grefte S (2015) Live-cell assessment of mitochondrial reactive oxygen species using dihydroethidine. In: Methods in Molecular Biology. Springer New York, New York, NY, pp 161-169

Franco R, Schoneveld O, Georgakilas AG, Panayiotidis MI (2008) Oxidative stress, DNA methylation and carcinogenesis. Cancer Lett 266:6-11. doi: 10.1016/j.canlet.2008.02.026

Frigault MM, Lacoste J, Swift JL, Brown CM (2009) Live-cell microscopy - tips and tools. J Cell Sci 122:753-767. doi: 10.1242/jcs.033837

Fujikawa M, Kobayashi K, Kozawa T (2012) Direct oxidation of the [2Fe-2S] cluster in 
SoxR protein by superoxide: distinct differential sensitivity to superoxide-mediated signal transduction. J Biol Chem 287:35702-35708. doi: 10.1074/jbc.M112.395079

Giorgio M, Trinei M, Migliaccio E, Pelicci PG (2007) Hydrogen peroxide: a metabolic byproduct or a common mediator of ageing signals? Nat Rev Mol Cell Biol 8:722A-728.

Giustarini D, Dalle-Donne I, Tsikas D, Rossi R (2009) Oxidative stress and human diseases: Origin, link, measurement, mechanisms, and biomarkers. Crit Rev Clin Lab Sci 46:241281. doi: $10.3109 / 10408360903142326$

Glasbey CA (1993) An Analysis of Histogram-Based Thresholding Algorithms.

Gomes A, Fernandes E, Lima JLFC (2005) Fluorescence probes used for detection of reactive oxygen species. Journal of Biochemical and Biophysical Methods 65:45-80. doi: 10.1016/j.jbbm.2005.10.003

Gomes LC, Di Benedetto G, Scorrano L (2011) Essential amino acids and glutamine regulate induction of mitochondrial elongation during autophagy. Cell Cycle 10:2635-2639.

Grek CL, Zhang J, Manevich Y, et al (2013) Causes and Consequences of Cysteine SGlutathionylation. J Biol Chem 288:26497-26504. doi: 10.1074/jbc.R113.461368

Groitl B, Jakob U (2014) Thiol-based redox switches. Biochimica et Biophysica Acta (BBA) - Proteins and Proteomics 1844:1335-1343. doi: 10.1016/j.bbapap.2014.03.007

Gupta SC, Hevia D, Patchva S, et al (2012) Upsides and downsides of reactive oxygen species for cancer: the roles of reactive oxygen species in tumorigenesis, prevention, and therapy. Antioxidants \& Redox Signaling 16:1295-1322. doi: 10.1089/ars.2011.4414

Gutscher M, Pauleau A-L, Marty L, et al (2008) Real-time imaging of the intracellular glutathione redox potential. Nat Methods 5:553-559. doi: 10.1038/nmeth.1212

Gutscher M, Sobotta MC, Wabnitz GH, et al (2009) Proximity-based protein thiol oxidation by $\mathrm{H} 2 \mathrm{O} 2$-scavenging peroxidases. J Biol Chem 284:31532-31540. doi: 10.1074/jbc.M109.059246

Halliwell B, Gutteridge J (2007) The chemistry of free radicals and related "reactive species." In: Free Radicals in Biology and Medicine, 4 edn. Oxford University Press, pp 30-78

Hamanaka RB, Chandel NS (2010) Mitochondrial reactive oxygen species regulate cellular signaling and dictate biological outcomes. Trends in Biochemical Sciences 35:505-513. doi: 10.1016/j.tibs.2010.04.002

Han D, Antunes F, Canali R, et al (2003) Voltage-dependent anion channels control the release of the superoxide anion from mitochondria to cytosol. J Biol Chem 278:55575563. doi: 10.1074/jbc.M210269200

Hanson GT, Aggeler R, Oglesbee D, et al (2004) Investigating Mitochondrial Redox Potential with Redox-sensitive Green Fluorescent Protein Indicators. J Biol Chem 279:13044-13053. doi: 10.1074/jbc.M312846200

Harman D (1956) Aging: a theory based on free radical and radiation chemistry. J Gerontol 
$11: 298-300$.

Hu JJ, Wong N-K, Ye S, et al (2015) Fluorescent Probe HKSOX-1 for Imaging and Detection of Endogenous Superoxide in Live Cells and In Vivo. J Am Chem Soc. doi: $10.1021 /$ jacs. 5 b01881

Huang LK, Wang M (1995) Image thresholding by minimizing the measures of fuzziness.

Iannetti EF, Willems PHGM, Pellegrini M, et al (2015) Toward high-content screening of mitochondrial morphology and membrane potential in living cells. Int J Biochem Cell Biol. doi: 10.1016/j.biocel.2015.01.020

Invitrogen (2006) Reactive Oxygen Species (ROS) Detection Reagents. Invitrogen

Koopman WJH, Distelmaier F, Esseling JJ, et al (2008) Computer-assisted live cell analysis of mitochondrial membrane potential, morphology and calcium handling. Methods 46:304-311. doi: 10.1016/j.ymeth.2008.09.018

Koopman WJH, Nijtmans LGJ, Dieteren CEJ, et al (2010) Mammalian Mitochondrial Complex I: Biogenesis, Regulation, and Reactive Oxygen Species Generation. Antioxidants \& Redox Signaling 12:1431-1470. doi: 10.1089/ars.2009.2743

Koopman WJH, Verkaart S, van Emst-de Vries SE, et al (2006) Simultaneous quantification of oxidative stress and cell spreading using 5-(and-6)-chloromethyl-2 “,7 ”dichlorofluorescein. Cytom Part A 69A:1184-1192. doi: 10.1002/cyto.a.20348

Koopman WJH, Verkaart S, Visch HJ, et al (2007) Human NADH:ubiquinone oxidoreductase deficiency: radical changes in mitochondrial morphology? AJP: Cell Physiology 293:C22-C29. doi: 10.1152/ajpcell.00194.2006

Korshunov SS, Skulachev VP, Starkov AA (1997) High protonic potential actuates a mechanism of production of reactive oxygen species in mitochondria. FEBS Lett 416:15-18.

Lambeth JD (2004) NOX enzymes and the biology of reactive oxygen. Nat Rev Immunol 4:181-189. doi: $10.1038 /$ nri1312

Lebiedzinska M, Karkucinska-Wieckowska A, Giorgi C, et al (2010) Oxidative stressdependent p66Shc phosphorylation in skin fibroblasts of children with mitochondrial disorders. Bba-Gen Subjects 1797:952-960. doi: 10.1016/j.bbabio.2010.03.005

Lopert P, Patel M (2014) Nicotinamide Nucleotide Transhydrogenase (Nnt) Links the Substrate Requirement in Brain Mitochondria for Hydrogen Peroxide Removal to the Thioredoxin/Peroxiredoxin (Trx/Prx) System. J Biol Chem 289:15611-15620. doi: 10.1074/jbc.M113.533653

Loschen G, Azzi A, Richter C, Flohé L (1974) Superoxide radicals as precursors of mitochondrial hydrogen peroxide. FEBS Lett 42:68-72.

Lukyanov KA, Belousov VV (2014) Biochimica et Biophysica Acta. BBA - General Subjects 1840:745-756. doi: 10.1016/j.bbagen.2013.05.030 
Mailloux RJ, McBride SL, Harper M-E (2013) Unearthing the secrets of mitochondrial ROS and glutathione in bioenergetics. Trends in Biochemical Sciences 38:592-602. doi: 10.1016/j.tibs.2013.09.001

Marchi S, Giorgi C, Suski JM, et al (2012) Mitochondria-ros crosstalk in the control of cell death and aging. J Signal Transduct 2012:329635. doi: 10.1155/2012/329635

Marí M, Morales A, Colell A, et al (2013) Mitochondrial glutathione: features, regulation and role in disease. Bba-Gen Subjects 1830:3317-3328. doi: 10.1016/j.bbagen.2012.10.018

Markvicheva KN, Bilan DS, Mishina NM, et al (2011) A genetically encoded sensor for H2O2 with expanded dynamic range. Bioorg Med Chem 19:1079-1084. doi: 10.1016/j.bmc.2010.07.014

Matarrese P, Gambardella L, Cassone A, et al (2003) Mitochondrial membrane hyperpolarization hijacks activated $\mathrm{T}$ lymphocytes toward the apoptotic-prone phenotype: homeostatic mechanisms of HIV protease inhibitors. J Immunol 170:60066015.

Meyer AJ, Dick TP (2010) Fluorescent Protein-Based Redox Probes.

Miller EW, Tulyathan O, Tulyanthan O, et al (2007) Molecular imaging of hydrogen peroxide produced for cell signaling. Nat Chem Biol 3:263-267. doi: 10.1038/nchembio871

Mishina NM, Bogeski I, Bolotin DA, et al (2012) Can We See PIP3 and Hydrogen Peroxide with a Single Probe? Antioxidants \& Redox Signaling 17:505-512. doi: 10.1089/ars.2012.4574

Miwa S, Brand MD (2003) Mitochondrial matrix reactive oxygen species production is very sensitive to mild uncoupling. Biochem Soc Trans 31:1300-1301.

Moylan JS, Reid MB (2007) Oxidative stress, chronic disease, and muscle wasting. Muscle \& Nerve 35:411-429. doi: 10.1002/mus.20743

Muchir A, van Engelen B, Lammens M, et al (2003) Nuclear envelope alterations in fibroblasts from LGMD1B patients carrying nonsense Y259X heterozygous or homozygous mutation in lamin A/C gene. Exp Cell Res 291:352-362. doi: 10.1016/j.yexcr.2003.07.002

Murphy MP (2009) How mitochondria produce reactive oxygen species. Biochem J 417:113. doi: $10.1042 / \mathrm{BJ} 20081386$

Murphy MP (2012) Mitochondrial Thiols in Antioxidant Protection and Redox Signaling: Distinct Roles for Glutathionylation and Other Thiol Modifications. Antioxidants \& Redox Signaling 16:476-495. doi: 10.1089/ars.2011.4289

Naderi W, Lopez C, Pandey S (2006) Chronically increased oxidative stress in fibroblasts from Alzheimer's disease patients causes early senescence and renders resistance to apoptosis by oxidative stress. Mech Ageing Dev 127:25-35. doi:

10.1016/j.mad.2005.08.006 
Nakamura T, Lipton SA (2011) Redox modulation by S-nitrosylation contributes to protein misfolding, mitochondrial dynamics, and neuronal synaptic damage in neurodegenerative diseases. Cell Death Differ 18:1478-1486. doi: 10.1038/cdd.2011.65

Nathan C, Cunningham-Bussel A (2013) Beyond oxidative stress: an immunologist's guide to reactive oxygen species. Nat Rev Immunol 13:349-361. doi: 10.1038/nri3423

Nicholls DG (2012) Fluorescence measurement of mitochondrial membrane potential changes in cultured cells. Methods Mol Biol 810:119-133. doi: 10.1007/978-1-61779382-0_8

Pastore A, Piemonte F (2012) S-Glutathionylation signaling in cell biology: progress and prospects. Eur J Pharm Sci 46:279-292. doi: 10.1016/j.ejps.2012.03.010

Pattison DI, Davies MJ (2006) Actions of ultraviolet light on cellular structures. EXS 131157.

Poburko D, Santo-Domingo J, Demaurex N (2011) Dynamic regulation of the mitochondrial proton gradient during cytosolic calcium elevations. J Biol Chem 286:11672-11684. doi: 10.1074/jbc.M110.159962

Prime TA, Forkink M, Logan A, et al (2012) A ratiometric fluorescent probe for assessing mitochondrial phospholipid peroxidation within living cells. Free Radical Biology and Medicine 53:544-553. doi: 10.1016/j.freeradbiomed.2012.05.033

Rabut G, Ellenberg J (2004) Automatic real-time three-dimensional cell tracking by fluorescence microscopy. J Microsc 216:131-137. doi: 10.1111/j.00222720.2004.01404.x

Radi R, Cassina A, Hodara R, et al (2002) Peroxynitrite reactions and formation in mitochondria. Free Radical Biology and Medicine 33:1451-1464.

Rambold AS, Kostelecky B, Elia N, Lippincott-Schwartz J (2011) Tubular network formation protects mitochondria from autophagosomal degradation during nutrient starvation. P Natl Acad Sci Usa 108:10190-10195. doi: 10.1073/pnas.1107402108

Rasmussen HH, Hamilton EJ, Liu C-C, Figtree GA (2010) Reversible oxidative modification: implications for cardiovascular physiology and pathophysiology. Trends Cardiovasc Med 20:85-90. doi: 10.1016/j.tcm.2010.06.002

Rhee SG, Woo HA, Kil IS, Bae SH (2012) Peroxiredoxin Functions as a Peroxidase and a Regulator and Sensor of Local Peroxides. J Biol Chem 287:4403-4410. doi: 10.1074/jbc.R111.283432

Riahi Y, Cohen G, Shamni O, Sasson S (2010) Signaling and cytotoxic functions of 4hydroxyalkenals. Am J Physiol Endocrinol Metab 299:E879-E886. doi: 10.1152/ajpendo.00508.2010

Robinson KM, Janes MS, Beckman JS (2008) The selective detection of mitochondrial superoxide by live cell imaging. Nat Protoc 3:941-947. doi: 10.1038/nprot.2008.56

Robinson KM, Janes MS, Pehar M, et al (2006) Selective fluorescent imaging of superoxide 
in vivo using ethidium-based probes. P Natl Acad Sci Usa 103:15038-15043. doi: 10.1073/pnas.0601945103

Roumier T, Szabadkai G, Simoni A-M, et al (2006) HIV-1 protease inhibitors and cytomegalovirus vMIA induce mitochondrial fragmentation without triggering apoptosis. Cell Death Differ 13:348-351. doi: 10.1038/sj.cdd.4401750

Saaranen MJ, Ruddock LW (2013) Disulfide bond formation in the cytoplasm. Antioxidants \& Redox Signaling 19:46-53. doi: 10.1089/ars.2012.4868

Sachdev S, Davies KJA (2008) Production, detection, and adaptive responses to free radicals in exercise. Free Radical Biology and Medicine 44:215-223. doi:

10.1016/j.freeradbiomed.2007.07.019

Sahoo PK, Soltani S, Wong A, Chen YC (1988) A survey of thresholding techniques.

Salmon AB, Richardson A, Perez VI (2010) Update on the oxidative stress theory of aging: Does oxidative stress play a role in aging or healthy aging? Free Radical Biology and Medicine 48:642-655. doi: 10.1016/j.freeradbiomed.2009.12.015

Sieprath T, Corne TDJ, Nooteboom M, et al (2015) Sustained accumulation of prelamin a and depletion of lamin $\mathrm{a} / \mathrm{c}$ both cause oxidative stress and mitochondrial dysfunction but induce different cell fates. Nucleus 6:1-11. doi: 10.1080/19491034.2015.1050568

Sieprath T, Darwiche R, De Vos WH (2012) Lamins as mediators of oxidative stress. Biochemical and Biophysical Research Communications 421:635-639. doi: 10.1016/j.bbrc.2012.04.058

Smith RL, De Vos WH, de Boer R, et al (2015) In Vivo Visualization and Quantification of Mitochondrial Morphology in C. elegans. In: Methods in Molecular Biology. Springer New York, New York, NY, pp 367-377

Staljanssens D, De Vos WH, Willems P, et al (2012) Time-resolved quantitative analysis of CCK1 receptor-induced intracellular calcium increase. Peptides 34:219-225. doi: 10.1016/j.peptides.2011.02.014

Stangherlin A, Reddy AB (2013) Regulation of circadian clocks by redox homeostasis. J Biol Chem 288:26505-26511. doi: 10.1074/jbc.R113.457564

Szabó C, Ischiropoulos H, Radi R (2007) Peroxynitrite: biochemistry, pathophysiology and development of therapeutics. Nat Rev Drug Discov 6:662-680. doi: 10.1038/nrd2222

Tarpey MM, Wink DA, Grisham MB (2004) Methods for detection of reactive metabolites of oxygen and nitrogen: in vitro and in vivo considerations. Am J Physiol-Reg I 286:R43144. doi: 10.1152/ajpregu.00361.2003

Thomas C, Mackey MM, Diaz AA, Cox DP (2009) Hydroxyl radical is produced via the Fenton reaction in submitochondrial particles under oxidative stress: implications for diseases associated with iron accumulation. Redox Report 14:102-108. doi: $10.1179 / 135100009 X 392566$

Topell S, Hennecke J, Glockshuber R (1999) Circularly permuted variants of the green 
fluorescent protein. FEBS Lett 457:283-289.

Touzet O, Philips A (2010) Resveratrol protects against protease inhibitor-induced reactive oxygen species production, reticulum stress and lipid raft perturbation. Aids 24:14371447. doi: 10.1097/QAD.0b013e32833a6114

Traber MG, Stevens JF (2011) Vitamins C and E: beneficial effects from a mechanistic perspective. Free Radical Biology and Medicine 51:1000-1013. doi: 10.1016/j.freeradbiomed.2011.05.017

Trudeau K, Molina AJA, Roy S (2011) High Glucose Induces Mitochondrial Morphology and Metabolic Changes in Retinal Pericytes. Investigative Ophthalmology \& Visual Science 52:8657-8664. doi: 10.1167/iovs.11-7934

Turrens JF (2003) Mitochondrial formation of reactive oxygen species. The Journal of Physiology 552:335-344. doi: 10.1113/jphysiol.2003.049478

Verkaart S, Koopman WJH, van Emst-de Vries SE, et al (2007) Superoxide production is inversely related to complex I activity in inherited complex I deficiency. Bba-Gen Subjects 1772:373-381. doi: 10.1016/j.bbadis.2006.12.009

Verstraeten VLRM, Broers JLV, van Steensel MAM, et al (2006) Compound heterozygosity for mutations in LMNA causes a progeria syndrome without prelamin A accumulation. Hum Mol Genet 15:2509-2522. doi: 10.1093/hmg/dd1172

Wang X, Fang H, Huang Z, et al (2013) Imaging ROS signaling in cells and animals. J Mol Med 91:917-927. doi: 10.1007/s00109-013-1067-4

Weisiger RA, Fridovich I (1973) Superoxide Dismutase.

Willems PHGM (2015) Perspective. 1-12. doi: 10.1016/j.cmet.2015.06.006

Winterbourn CC (2008) Reconciling the chemistry and biology of reactive oxygen species. Nat Chem Biol 4:278-286. doi: 10.1038/nchembio.85

Woolley JF, Stanicka J, Cotter TG (2013) Recent advances in reactive oxygen species measurement in biological systems. Trends in Biochemical Sciences 38:556-565. doi: 10.1016/j.tibs.2013.08.009

Xiang T, Du L, Pham P, et al (2015) Nelfinavir, an HIV protease inhibitor, induces apoptosis and cell cycle arrest in human cervical cancer cells via the ROS-dependent mitochondrial pathway. Cancer Lett 364:79-88. doi: 10.1016/j.canlet.2015.04.027

Yu TZ, Robotham JL, Yoon Y (2006) Increased production of reactive oxygen species in hyperglycemic conditions requires dynamic change of mitochondrial morphology. P Natl Acad Sci Usa 103:2653-2658. doi: 10.1073/pnas.0511154103

Zhao B, Bilski PJ, He Y-Y, et al (2008) Photo-induced reactive oxygen species generation by different water-soluble fullerenes (C) and their cytotoxicity in human keratinocytes. Photochem Photobiol 84:1215-1223. doi: 10.1111/j.1751-1097.2008.00333.x

Zhao H, Kalivendi S, Zhang H, et al (2003) Superoxide reacts with hydroethidine but forms a 
fluorescent product that is distinctly different from ethidium: potential implications in intracellular fluorescence detection of superoxide. Free Radical Biology and Medicine 34:1359-1368.

Zheng M, Aslund F, Storz G (1998) Activation of the OxyR transcription factor by reversible disulfide bond formation. Science 279:1718-1721.

Zielonka J, Kalyanaraman B (2010) Hydroethidine- and MitoSOX-derived red fluorescence is not a reliable indicator of intracellular superoxide formation: Another inconvenient truth. Free Radical Biology and Medicine 48:983-1001. doi: 10.1016/j.freeradbiomed.2010.01.028

Zuiderveld K (1994) Contrast limited adaptive histogram equalization. Academic Press Professional, Inc. 